\title{
Vibration Response Analysis of Simply Supported Box Girder Bridge-Maglev Train in Accelerated Test of Changsha Maglev Express
}

\author{
Xiao Liang, ${ }^{1,2}$ Tianyong Jiang, ${ }^{1}$ Yue Hong, ${ }^{3}$ Jiabing Zhang, ${ }^{1}$ Mai Jiang $\left(\mathbb{D},{ }^{1}\right.$ \\ and Zeyin Wang $\mathbb{D}^{1}$ \\ ${ }^{1}$ School of Civil Engineering, Changsha University of Science and Technology, Changsha 410114, China \\ ${ }^{2}$ Hunan Maglev Technology Research Center Co.,Ltd., Changsha 410000, China \\ ${ }^{3}$ Guangxi Transportation Science and Technology Group Co.,Ltd., Nanning 530007, China
}

Correspondence should be addressed to Mai Jiang; jiangmai1995@163.com and Zeyin Wang; wangzeyin255@163.com

Received 11 July 2020; Revised 30 September 2020; Accepted 9 November 2020; Published 30 November 2020

Academic Editor: Sakar Mohan

Copyright (c) 2020 Xiao Liang et al. This is an open access article distributed under the Creative Commons Attribution License, which permits unrestricted use, distribution, and reproduction in any medium, provided the original work is properly cited.

In order to study and analyze the vibration response of simply supported box girder bridge-maglev vehicle, a $25 \mathrm{~m}$ span simply supported box girder bridge of Changsha Maglev Express was selected as the research object. Field tests were carried out to explore the dynamic response of maglev vehicle running on the bridge. Firstly, the dynamic characteristics of the bridge under the action of medium-low speed maglev train at different speeds were analyzed, and the vibration response of vehicle and bridge was studied at the design speed of $60 \sim 130 \mathrm{~km} / \mathrm{h}$. Among them, the longitudinal acceleration of simply supported box girder ranged from $60 \mathrm{~km} / \mathrm{h}$ to $130 \mathrm{~km} / \mathrm{h}$, which increased linearly with the speed of the train and reached the maximum $0.59 \mathrm{~m} / \mathrm{s}^{2}$. Its longitudinal deflection also increased with the increase in train speed, which reached the maximum $1.605 \mathrm{~mm}$ at $130 \mathrm{~km} / \mathrm{h}$. When the speed is $130 \mathrm{~km} / \mathrm{h}$, the suspension gap of the maglev vehicle was concentrated in the range of $7.24 \sim 11.50 \mathrm{~mm}$. Through the test analysis, this study provides a basis for the vibration response analysis of simply supported box girder bridge-maglev train. It also provides a reference for the modification and formulation of relevant specifications and experimental verification for the acceleration work of medium-low speed maglev train in the future.

\section{Introduction}

Maglev transportation is a kind of rail transportation which uses electromagnetic force to levitate, guide, and drive rail trains. Maglev railway is obviously different from the existing common wheel-rail railway, which is the development and continuation of the common wheel-rail railway. Maglev trains are expected to replace the traditional wheelrail system of medium-low speed public transport [1]. Among them, the medium-low speed maglev train has a broad application prospect due to its low energy consumption, vibration, and noise [2].

Relevant research has carried out many studies on the vibration response analysis of the maglev train-bridge system. In particular, since the 1970s and 1980s, some scholars have begun to pay attention to the dynamic analysis of maglev train-guide rail interaction [3]. Gottzein found that the controller was an important reason for the self-excited vibration of the maglev train-bridge coupling system without considering the elasticity of the track beam [4-6]. Han et al. studied the response of the track beam with different flexural span ratios in the vehicle-bridge coupling dynamic system. They proposed that the limit of L/2000 flexural span ratio could meet various performance requirements under the dynamic action of train and constructed a test line of a bridge with a height of $1.6 \mathrm{~m}$ and a length of $25 \mathrm{~m}$ to verify its limit [7]. Lee researched the stiffness limit of the maglev bridge from the perspective of comfort. He established the vehicle-bridge coupling model and analyzed the performance of suspension gap and vehicle acceleration in the coupling model with different train running speeds, track beam spans, and the natural frequency 
and damping ratio of two-system suspension [8]. Kong et al. studied the maglev train-bridge coupling vibration problem from the perspective of the suspension controller. They established a 5-DOF (degree of freedom) train-rail beam coupling model considering the smoothness of track and proposed the sliding-mode control method based on the Kalman filter to control the dynamic response of suspension system at different given operating speeds [9].

Shi et al. established a train-controller-bridge model for the maglev train-bridge system and discussed the effect of train-bridge system parameters and controller model on the dynamic response of the system $[10,11]$. Kim et al. proposed an experimental development of levitation control for highprecision maglev transmission systems carrying OLED displays to monitor and obtain real-time measurement values to manipulate the maglev system [12]. Schmid et al. proposed a nonlinear magnet model including magnetic saturation for the control design of magnetic levitation vehicles, which corresponds to the measured values obtained from the test bench [13]. Zhang and Huang proposed a maglev vehicle/track interaction model based on field measurement and model update methods. Based on the onsite measurement, the frequency response of the guide rail under the excitation of the maglev vehicle is analyzed [14]. Wilson and Biggers simulated the operation of a high-speed air-flotation train on the bridge by moving uniform force and studied the relationship between the resonance speed of rail and the vibration amplitude of bridge [15]. Chiu et al. studied the interaction between track beams by a model of elastic track beams placed on rigid piers [16]. Based on Chiu's track model, Katz et al. established two train-rail coupling models of attraction and repulsion for maglev trains and pointed out the feasibility of maglev trains running on elastic tracks at a speed of $300 \mathrm{~km} / \mathrm{h}$ [17]. Smith and Wormley analyzed the dynamic response of the elastic track beam when the maglev train ran on the track beam at different speeds and introduced the dynamic amplification coefficient and deflection distribution of guide rail under the action of concentrated force [18]. Cai et al. simulated the two-system suspension system and the simplified model of moving load-track beam and explored the coupling vibration of the high-speed maglev train-elastic beam [19]. Yau and Kwona investigated the effect of wind on the coupling vibration of the maglev train-bridge system [20-22].

However, maglev technology still has very large improvement space. For example, when the maglev train passes through the bridge section, the bridge has a significant influence on the suspension stability and dynamic response of the train. Strong train-bridge coupling vibration problems appeared in maglev trains, such as TR04 in Germany, AMT in the United States, HSST03 in Japan, UTM in South Korea, CMS in Tangshan, TR08 in Shanghai, and Maglev Express in Changsha all experienced, which even caused suspension failure [23-25]. Therefore, less medium-low speed Maglev Express has been opened to traffic, and relevant field tests of actual operating lines are also relatively scarce.

In this study, a $25 \mathrm{~m}$ span simply supported box girder of Changsha Maglev Express was taken as the research object. The dynamic strain, acceleration, and deflection of the simply supported box girder, as well as the acceleration and suspension gap of suspension frame of maglev train, were tested to analyze the vibration response of simply supported box girder bridge-maglev train. This study provides an experimental basis for the safe and effective acceleration of medium-low speed maglev train in the future, and a reference for the application of the simply supported box girder in medium-low speed maglev system engineering.

\section{Composition and Parameters of the Vehicle- Track Beam System}

2.1. Vehicle Description and Main Parameters. The research object of this study is a medium speed maglev train with short-stator asynchronous traction. Figure 1 shows the medium-low speed maglev train in this experiment.

The normal conducting EMS (electromagnetic suspension) guiding technique and SLIM (short-stator linear induction motor) traction technique were used in this train. Its main technical specifications are shown in Table 1. Among them, the electromagnetic attractive force was used to overcome the train weight in the EMS system. However, it is directly proportional to the square of suspension current and inversely proportional to the square of suspension gap, which causes the open-loop of the suspension system to be unstable. In order to make the suspension gap reach the expected value, the suspension controller was designed to impose active control [23-26].

2.2. Main Structure of Track Beam. For the experimental rail beam in this study, it is composed of a rail beam, rail platform, and fasteners connecting sleeper and rail platform. The track structure installed on the rail platform is called the track bar, which is composed of H-beam steel sleeper, F-beam steel, aluminum induction plate of linear motor, and connecting bolts. This structure can be used in bridge, roadbed, and tunnel.

The layout of the steel structure sleeper system mainly includes an aluminum induction plate, $\mathrm{F}$ rail, expansion joint, and bridge rail platform. Comparative analysis shows that the multilayer combination of the structure is like the traditional railway track. At the same time, in the process of operation, the load and vibration of the train can be continuously transmitted through the F rail, sleeper, and so on and finally reach the line foundation. This kind of mediumlow speed maglev track structure has obvious advantages so that it is applied with the largest proportion. Figure 2 shows the suspension system of the medium-low speed maglev system.

\section{Test Details}

Changsha Maglev Express starts at Changsha South Railway Station and ends at Changsha Huanghua International Airport, with the Langli Station in the middle. It is $18.54 \mathrm{~km}$ long and runs at a speed of $100 \mathrm{~km} / \mathrm{h}$. In order to achieve medium speed for the newly-built maglev line, relevant research was carried out on the existing maglev line. The test 


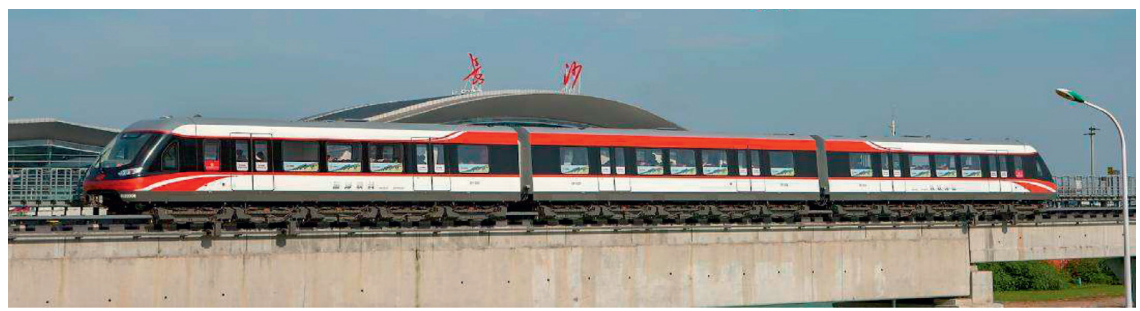

Figure 1: Medium-low speed maglev train of Changsha Maglev Express.

TABLE 1: Main technical specifications of the train.

\begin{tabular}{|c|c|c|c|}
\hline \multirow{2}{*}{ Number } & \multirow{2}{*}{ Technical specifications } & \multicolumn{2}{|c|}{ Type of train } \\
\hline & & End & Middle \\
\hline 1 & Basic train length $(\mathrm{mm})$ & 16500 & 15600 \\
\hline 2 & Basic train width $(\mathrm{mm})$ & & \\
\hline 3 & Maximum train height $(\mathrm{mm})$ & & \\
\hline 4 & Net height inside the train $(\mathrm{mm})$ & & \\
\hline 5 & Floor height (mm) & & \\
\hline 6 & AW0 train weight $(\mathrm{t})$ & & \\
\hline 7 & Train suspension ability $(\mathrm{t})$ & & \\
\hline 8 & Number of suspension frame modules & & \\
\hline 9 & Length of suspension frame modules (mm) & & \\
\hline 10 & Rail gauge $(\mathrm{mm})$ & & \\
\hline 11 & Rated suspension gap (mm) & & \\
\hline 12 & Height of centerline of coupler (mm) & & \\
\hline 13 & Number of doors on each side of the train vehicle & & \\
\hline 14 & Starting acceleration $\left(\mathrm{m} / \mathrm{s}^{2}\right)$ & & \\
\hline 15 & Common braking deceleration $\left(\mathrm{m} / \mathrm{s}^{2}\right)$ & & \\
\hline 16 & Emergency braking deceleration $\left(\mathrm{m} / \mathrm{s}^{2}\right)$ & & \\
\hline
\end{tabular}

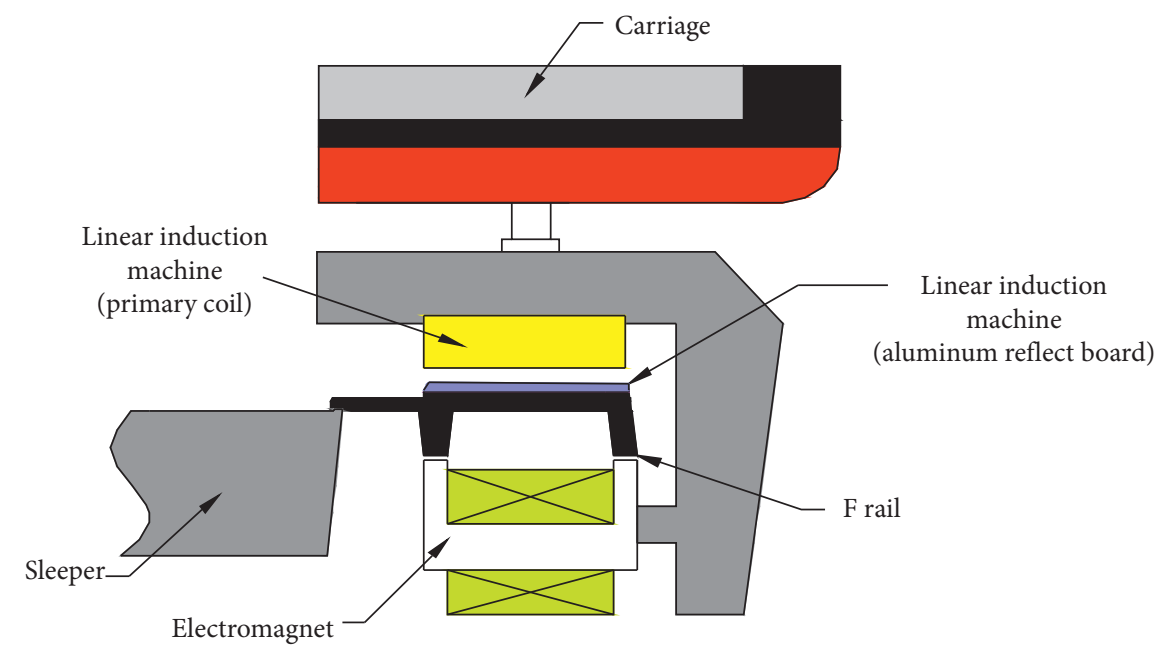

FIgURE 2: Suspension system of the medium-low speed maglev train.

line is the upper line of Changsha South Railway Station to Langli Station (YDK0 +098 YDK7 +578). Among them, the highest speed section is YDK4+200 YDK6 +000 . Therefore, $25 \mathrm{~m}$ simply supported box girder was selected to be connected to the south side for monitoring. The simply supported test box girder is shown in Figure 3.

The dynamic strain, acceleration, and deflection of $25 \mathrm{~m}$ simply supported box girder, as well as the acceleration and suspension gap of train suspension frame, were tested in this study. A total of 6 strain measuring points and 5 acceleration measuring points were laid out for $25 \mathrm{~m}$ simply supported box girder, as shown in Table 2 and Figures 4-5. Among them, the measuring points of dynamic deflection were arranged in the midspan position.

In this experiment, the photos of site installation and detection of dynamic strain and acceleration of $25 \mathrm{~m}$ simply supported box girder are shown in Figure 6. The acceleration sensor was Shanghai Beizhi 17100, and test accuracy was 


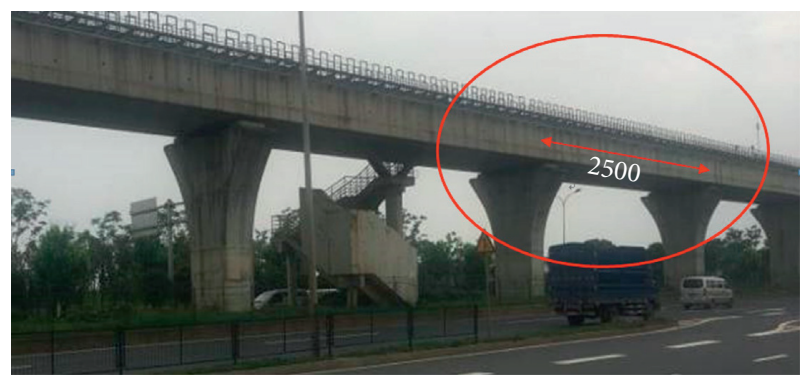

(a)

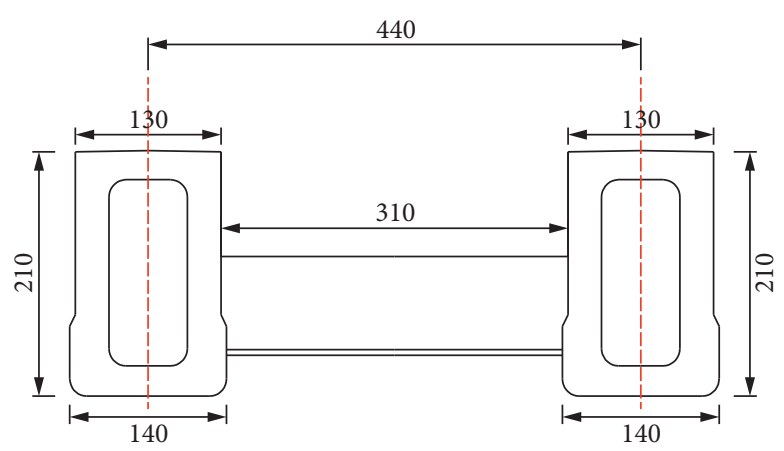

(b)

FIgURE 3: The simply supported test box girder (unit: $\mathrm{cm}$ ). (a) Test span. (b) Cross section.

TABLE 2: Location of dynamic strain and acceleration.

\begin{tabular}{lcc}
\hline Name & Number & Location \\
\hline & $\varepsilon 1$ & Bottom plate center at $1 / 4$ of upline \\
Dynamic strain & $\varepsilon 2$ & Bottom plate center at midspan of upline \\
& $\varepsilon 3$ & Bottom plate center at $3 / 4$ of upline \\
& $\varepsilon 5$ & Bottom plate center at $1 / 4$ of downline \\
& $\varepsilon 6$ & Bottom plate center at midspan of downline \\
& a1 & Bottom plate center at $3 / 4$ of downline \\
Acceleration & a2 & a3 \\
& a4 & Vertical acceleration of bottom plate center at $1 / 4$ of upline \\
& a5 & Vertical acceleration of bottom plate center at midspan of upline \\
& & Transverse acceleration of bottom plate center at midspan of upline \\
& Longitudinal acceleration of bottom plate center at $3 / 4$ of upline \\
\end{tabular}

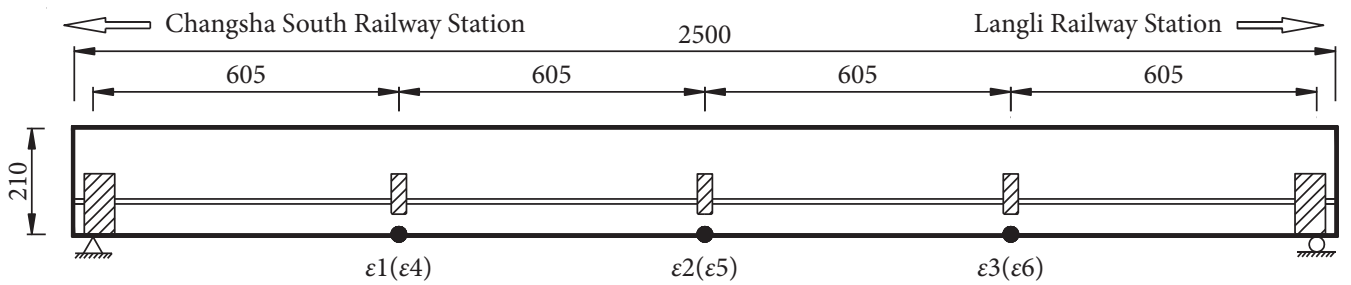

(a)

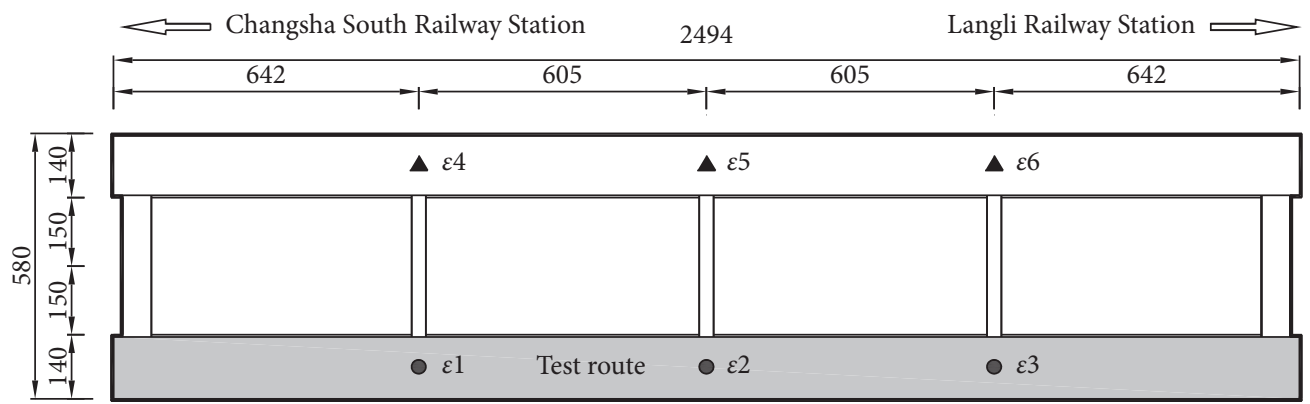

(b)

FIgURE 4: Layout of dynamic strain measuring point (unit: $\mathrm{cm}$ ). (a) Floor plan. (b) Overhead view.

$980 \mathrm{mv} / \mathrm{g}$. The strain gain was utilized to respond to the dynamic signal. At the test location, the dynamic signal test analysis system (system model: DH3822) was used to measure dynamic strain and acceleration, the sampling rate is $200 \mathrm{~Hz}$, as shown in Figure 6(b). Dynamic displacement of midspan of simply supported box girder was monitored by using the Multipoint Dynamic Video Measurement System (system model: SMTN-X), the resolution is $\pm 0.02 \mathrm{~mm}$ per 


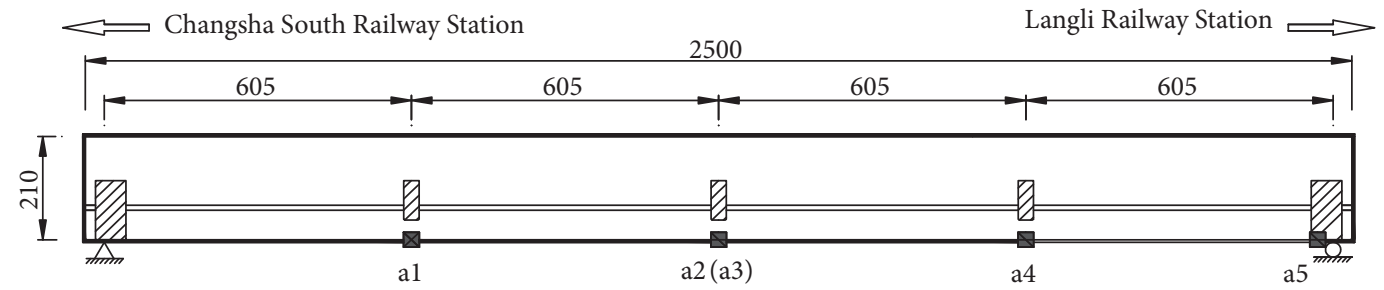

(a)

$\rightleftharpoons$ Changsha South Railway Station $\quad$ Langli Railway Station $\Longrightarrow$
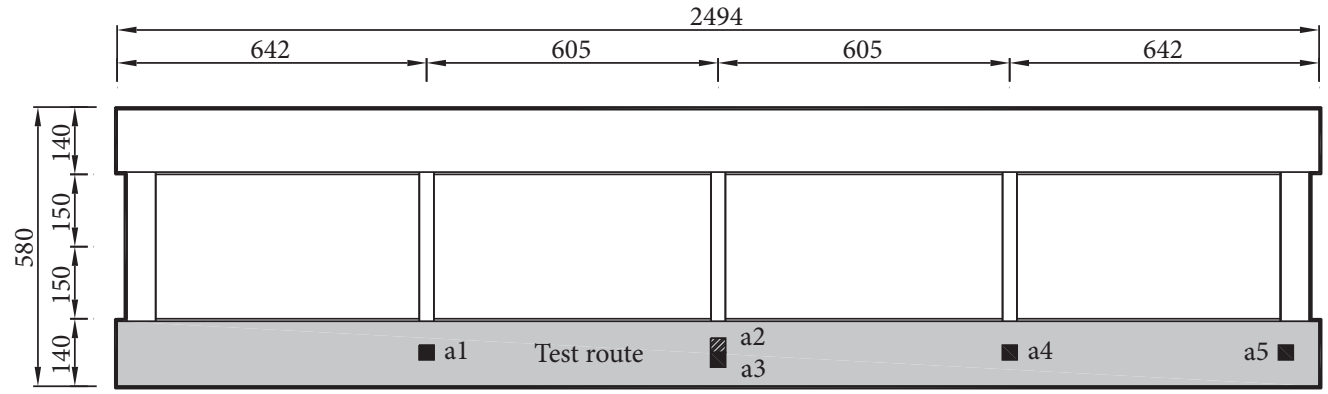

(b)

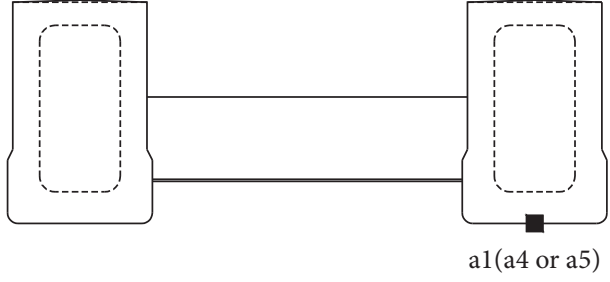

Other sections

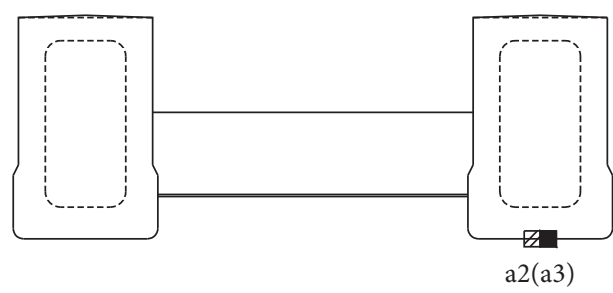

Midspan section

(c)

Figure 5: Layout of acceleration measuring point (unit: $\mathrm{cm}$ ). (a) Floor plan. (b) Overhead view. (c) Cross section.

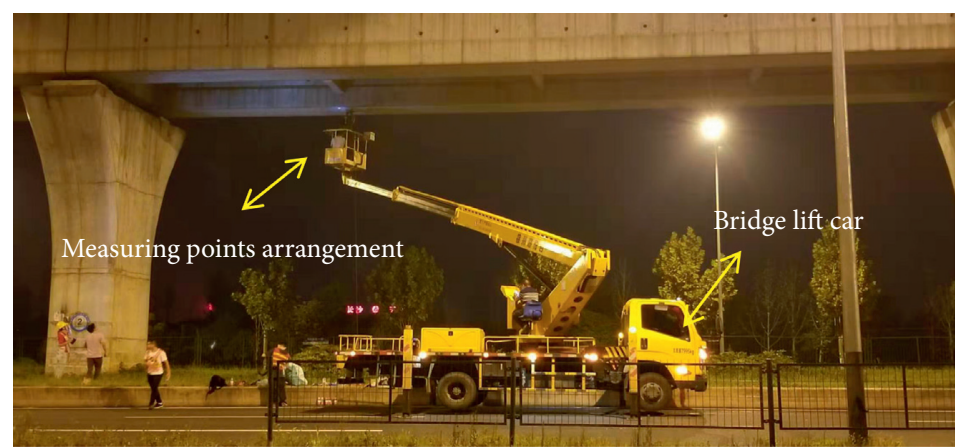

(a)

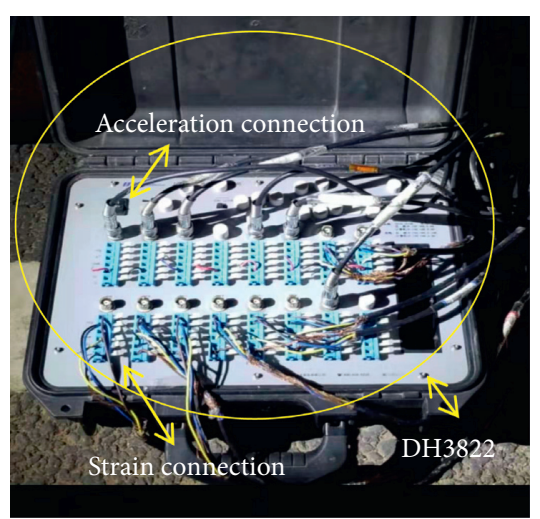

(b)

FIgURE 6: Continued. 


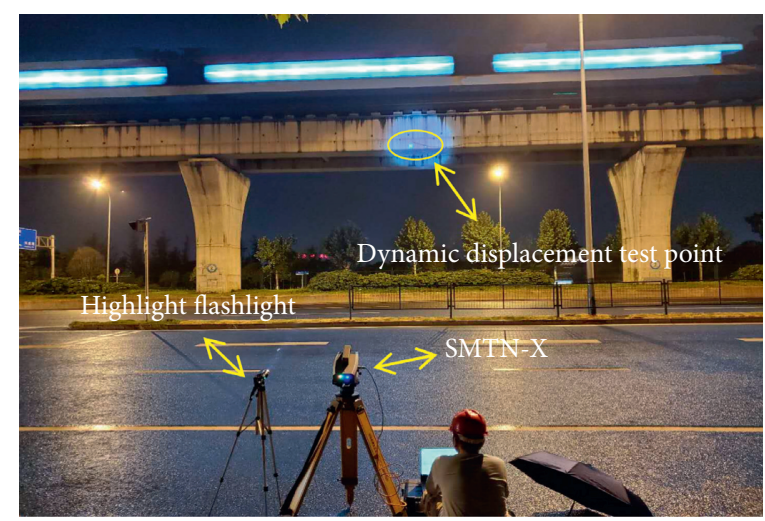

(c)

Figure 6: The photos of the test. (a) Measuring points arrangement. (b) Strain and acceleration test. (c) Dynamic displacement test.

$10 \mathrm{~m}$, and test distance is $0.1 \sim 500 \mathrm{~m}$. The Changsha maglev train needs to operate during the day, so the speedup test can only be carried out after the train is out of service at night. When the dynamic monitoring system monitors the dynamic displacement of the bridge at night, it is difficult to find the target point, and the accuracy is also very low, so it is difficult to meet the practical needs of the project. Therefore, in order to improve the test accuracy of the dynamic displacement instrument, Lycra reflectors are used on the test beam, and a light source with high brightness is also used, as shown in Figure 6(c).

In the test, acceleration and suspension gap of suspension frame of the Maglev train were monitored; their measurement points are shown in Figure 7. The acceleration of the suspension frame can be obtained by using the Dynamic signal test analysis system DH3822. The eddy-current transducers installed in the suspension were used to monitor the suspension gap. The speedup test of Changsha Maglev Express was divided into nine test conditions according to the speeds of $60 \mathrm{~km} / \mathrm{h}, 70 \mathrm{~km} / \mathrm{h}, 80 \mathrm{~km} / \mathrm{h}, 90 \mathrm{~km} / \mathrm{h}, 100 \mathrm{~km} /$ h, $110 \mathrm{~km} / \mathrm{h}, 120 \mathrm{~km} / \mathrm{h}, 125 \mathrm{~km} / \mathrm{h}$, and $130 \mathrm{~km} / \mathrm{h}$. According to this speed setting, the train passed through $25 \mathrm{~m}$ simply supported box girder at a uniform speed, and the dynamic response value of the corresponding position of the bridge was tested.

\section{Dynamic Response of Bridge Structure}

4.1. Dynamic Strain. Six dynamic strain points were arranged on the simply supported beam, and their dynamic strain value changed at eight different speeds, including $60 \mathrm{~km} / \mathrm{h}, 80 \mathrm{~km} / \mathrm{h}, 90 \mathrm{~km} / \mathrm{h}, 100 \mathrm{~km} / \mathrm{h}, 110 \mathrm{~km} / \mathrm{h}, 120 \mathrm{~km} / \mathrm{h}$, $125 \mathrm{~km} / \mathrm{h}$, and $130 \mathrm{~km} / \mathrm{h}$, as shown in Figure 8. In Figure 8, the dynamic strain changes of six measuring points of simply supported box girder at eight different maglev train speeds in one minute were required to be collected.

It can be seen from Figure 8 that, before the maglev train arrives at the simply supported box girder, the dynamic strain of the simply supported box girder remains at zero. However, as the train moves into the box girder, the strain at the measuring point will suddenly increase. The dynamic strain of the bridge is maintained in a stable range within 2 to $4 \mathrm{~s}$ of maglev running on the bridge, which is slightly below the maximum value. Then, the moment the train leaves the simply supported box girder, the strain suddenly reaches a maximum value, which decreases to zero as the train leaves.

Under the conditions of eight different speeds of train running along the upline, the maximum strain of six measuring points on the floor of the bridge is less than $20 \mu \varepsilon$. Moreover, with the increase in train speed, the strain value of measuring point $\varepsilon 2$ on the bottom plate of the middle span of the bridge is greater than that of $\varepsilon 1$ at $1 / 4$ of the bottom plate and $\varepsilon 3$ at $3 / 4$ of the bottom plate. However, the dynamic strain of $\varepsilon 3$ is greater than that of $\varepsilon 1$. The reason is that the train will generate an impact force at $3 / 4$ of the bridge bottom plate when it leaves the bridge. By analyzing the upline and downline of the bridge, it can be obtained that the dynamic strain of the measuring points on the bottom plate of the middle span of two lines is greater than that at $1 / 4$ and $3 / 4$ of the bottom plate. At the same time, the dynamic strain of the measuring points on the corresponding position of bridge upline is larger than that of the adjacent downline.

Figure 9 shows the variation of the maximum dynamic strain of bridge at eight different speeds of maglev train. The strain of typical measuring point $\varepsilon 2$ on the bottom plate of bridge upline only decreases slightly at the train speed of $60 \sim 100 \mathrm{~km} / \mathrm{h}$. Among them, it is $18.671 \mu \varepsilon$ and $17.747 \mu \varepsilon$, respectively, at the train speeds of $60 \mathrm{~km} / \mathrm{h}$ and $100 \mathrm{~km} / \mathrm{h}$. It decreases by $4.9 \%$ from the train speed of $60 \mathrm{~km} / \mathrm{h}$ to $100 \mathrm{~km} / \mathrm{h}$.

However, in the range of $100 \sim 130 \mathrm{~km} / \mathrm{h}$, the strain of $\varepsilon 2$ increases significantly with the increase in train speed. When the speed is $130 \mathrm{~km} / \mathrm{h}$, the strain of $\varepsilon 2$ is $19.308 \mu \varepsilon$. Compared with the strain at $100 \mathrm{~km} / \mathrm{h}$, it increases by about $8.80 \%$. For the strain of other measurement points, the pattern is less obvious. It should be noted that the test process is inevitably affected by external environmental factors. Therefore, the strain decreases slightly at $60 \sim 100 \mathrm{~km} / \mathrm{h}$.

4.2. Acceleration Time-Domain Analysis. In this section, the results of acceleration were processed, and the effect of acceleration on the dynamic characteristics of $25 \mathrm{~m}$ simply 


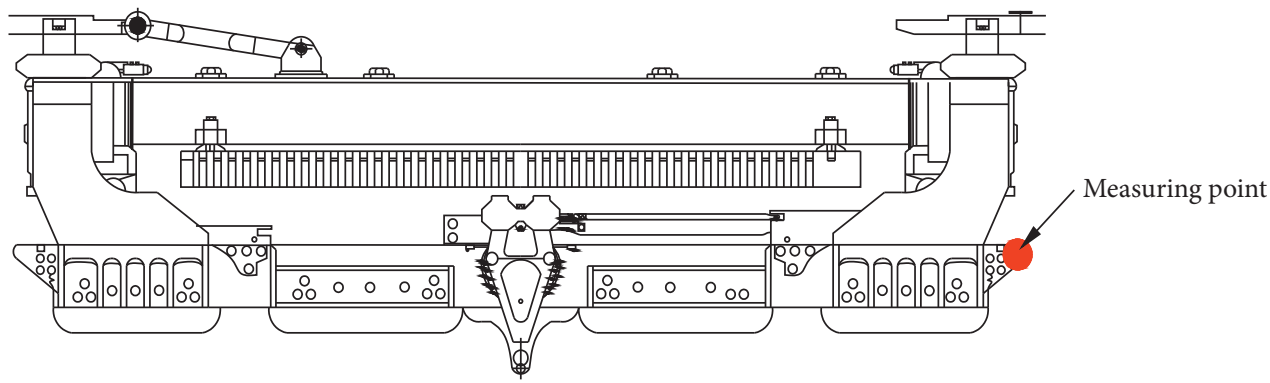

Figure 7: Measurement point of acceleration and suspension gap of suspension frame.
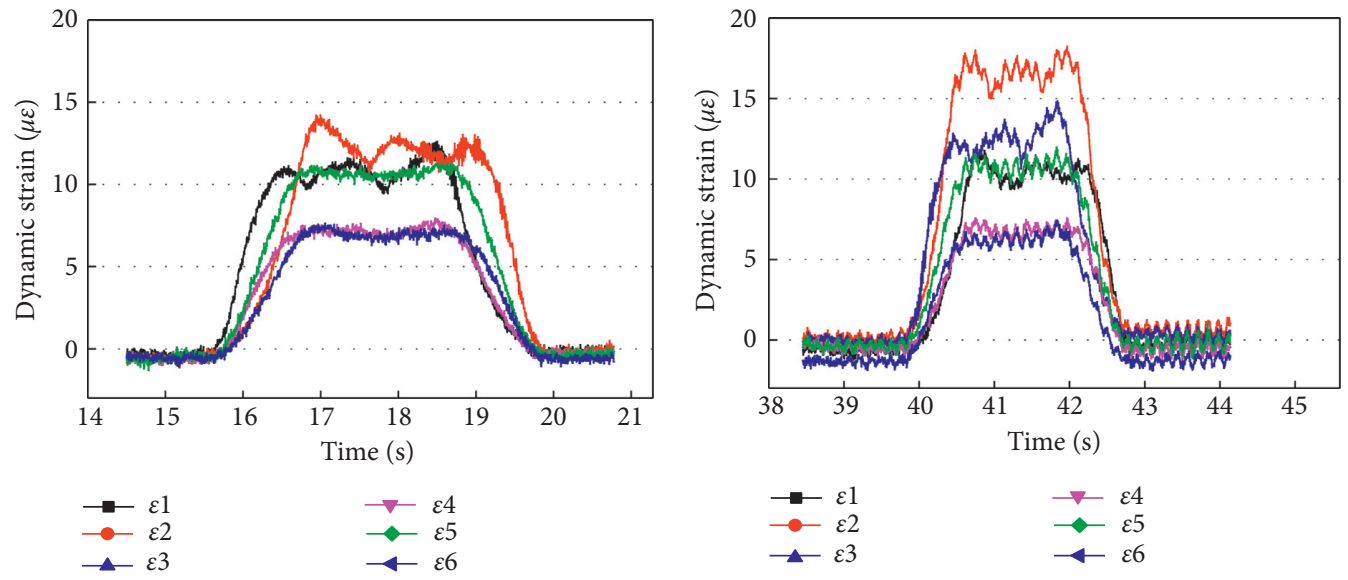

(a)

(b)
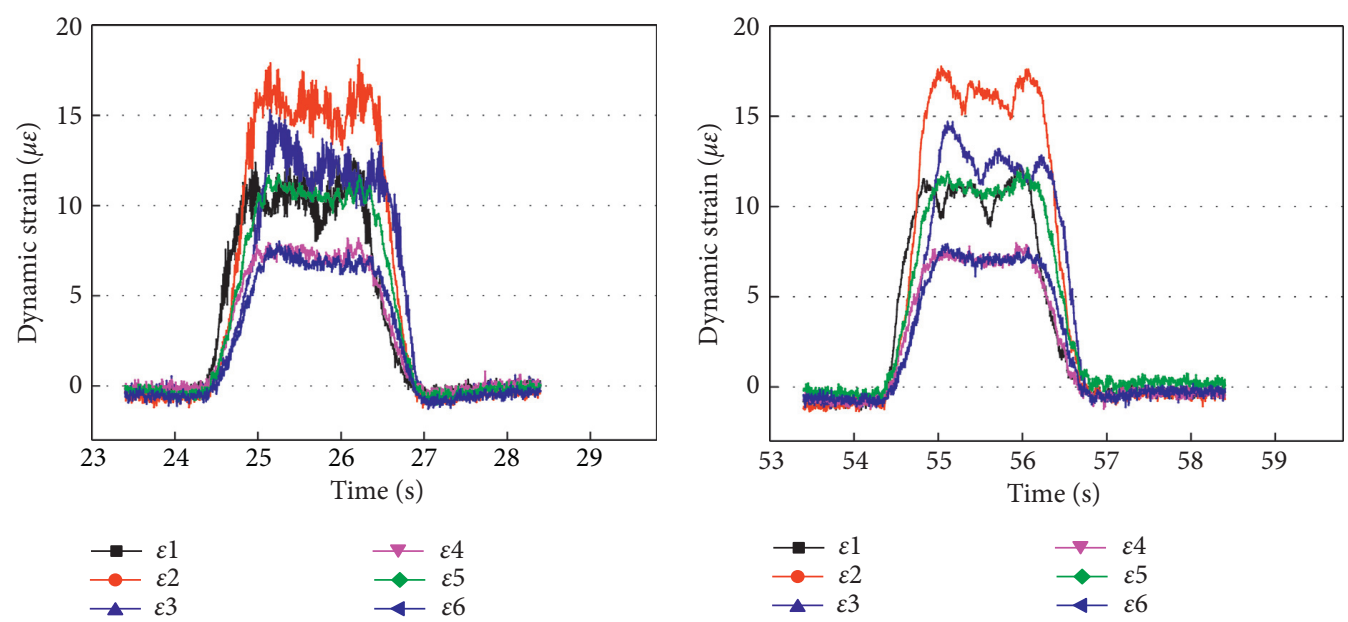

(c)

(d)

FIGURE 8: Continued. 

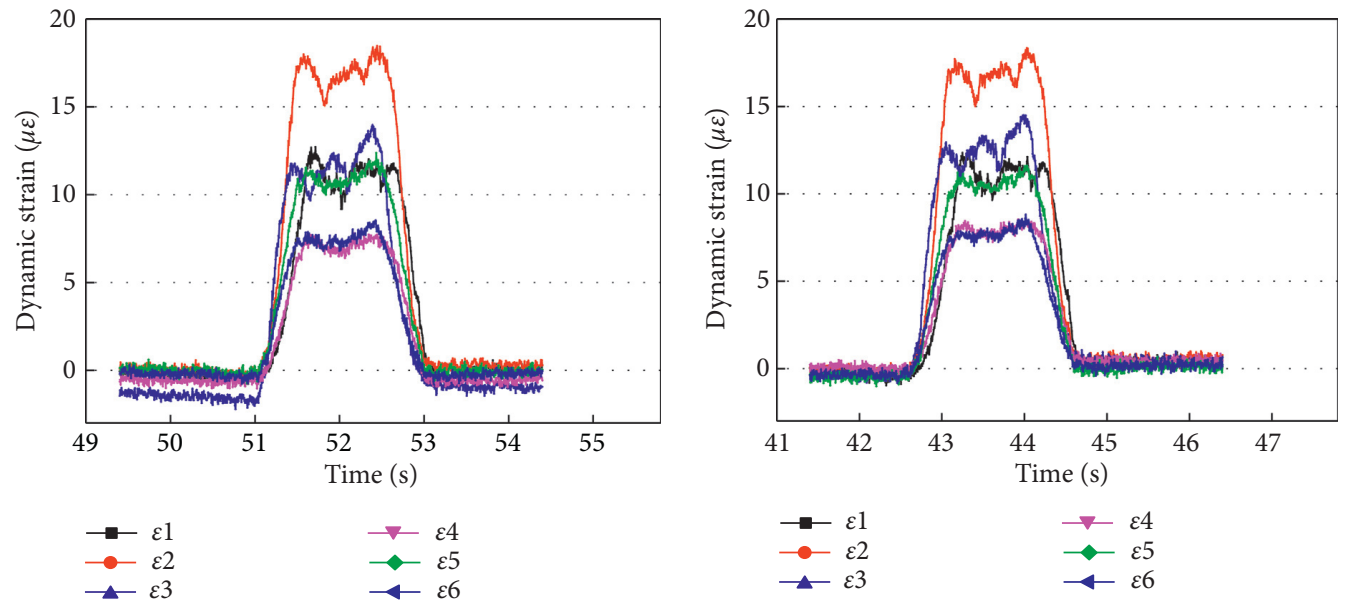

(e)

(f)

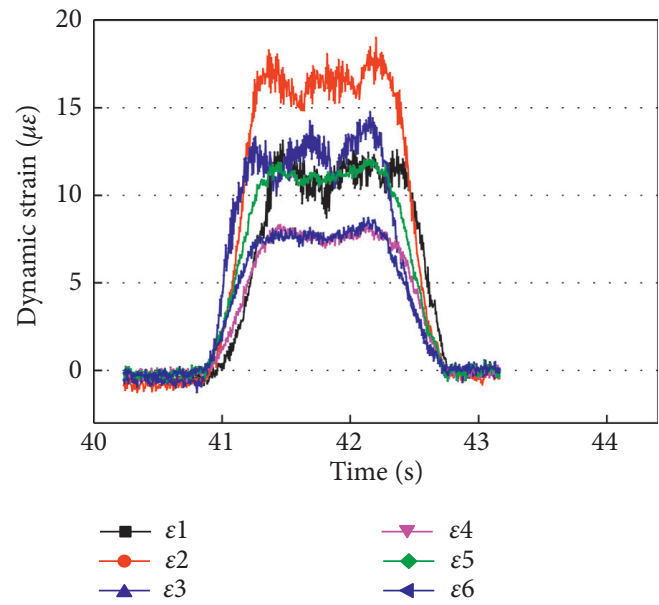

(g)

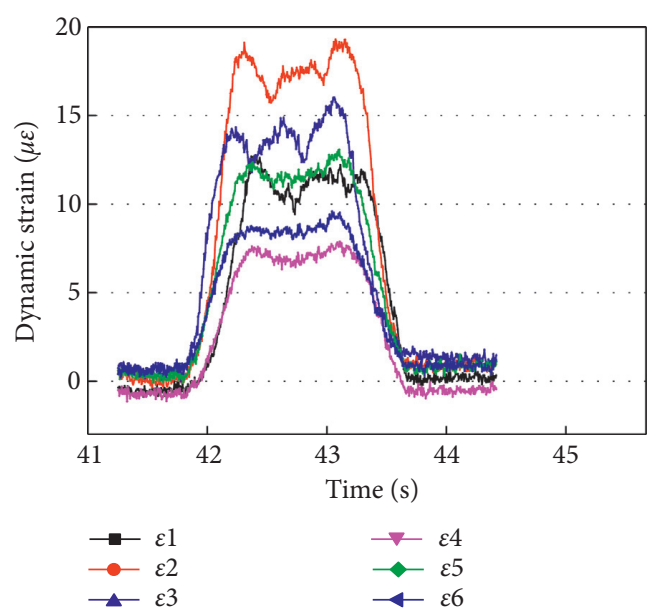

(h)

Figure 8: Variation of dynamic strain at eight different speeds. (a) $v=60 \mathrm{~km} / \mathrm{h}$. (b) $v=80 \mathrm{~km} / \mathrm{h}$. (c) $v=90 \mathrm{~km} / \mathrm{h}$. (d) $v=100 \mathrm{~km} / \mathrm{h}$. (e) $v=110 \mathrm{~km} / \mathrm{h}$. (f) $v=120 \mathrm{~km} / \mathrm{h}$. (g) $v=125 \mathrm{~km} / \mathrm{h}$. (h) $v=130 \mathrm{~km} / \mathrm{h}$.

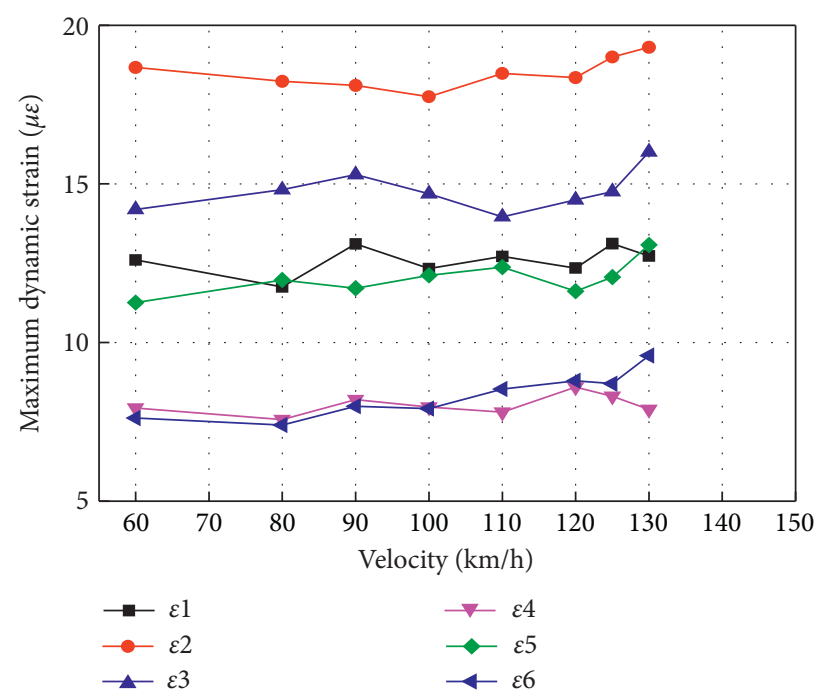

Figure 9: Variation of maximum dynamic strain at eight different speeds. 
supported box girder at different speeds was emphatically analyzed. In this $25 \mathrm{~m}$ simply supported box girder, a total of 5 acceleration measuring points were arranged. Among them, a1, a2, a4, and a5 are longitudinal acceleration measuring points, and a3 is a transverse acceleration measuring point. The midspan acceleration measuring point a2 was selected as a typical measuring point for analysis, and the relationship between the acceleration amplitude and the time course was studied in the whole process of the train from entering to leaving the simply supported box girder.

As shown in Figure 10, the acceleration time is about $4 \mathrm{~s}$ during the process of the train passing through the box girder. When the train enters the box girder, the acceleration is maintained around zero. As the train passes it, the acceleration reaches the maximum instantly. After the train leaves, the acceleration decreases with the forced vibration.

By comparing the peaks of all accelerations at different speeds, it can be seen that the maximum peaks are all lower than $0.59 \mathrm{~m} / \mathrm{s}^{2}$ and the train can still run safely up to $130 \mathrm{~km} /$ h. With the increase in train speed, the acceleration amplitude increases gradually, and the acceleration time decreases gradually. The reason is that with the increase in train speed, it takes less time for the train to pass through the simply supported box girder, and the vibration of the train to bridge is more and more obvious.

In Figure 11, in order to further explore the relationship between the acceleration and train speed, $a 2$ was taken as a typical measuring point and its maximum acceleration value was extracted for analysis. At the same time, the maximum acceleration measuring point al of quarter-span was taken as a reference. As shown in Figure 10, the midspan acceleration is larger than that of quarter-span at different train speeds. At $60 \mathrm{~km} / \mathrm{h}$, the midspan acceleration is $0.23 \mathrm{~m} / \mathrm{s}^{2}$. At the same time, at $130 \mathrm{~km} / \mathrm{h}$, the midspan acceleration is $0.59 \mathrm{~m} / \mathrm{s}^{2}$.

According to the trend of curve, in the range of $60 \sim 120 \mathrm{~km} / \mathrm{h}$, the peak acceleration has an almost linear relationship with the train speed. When the train speed is $120 \mathrm{~km} / \mathrm{h}$, the midspan acceleration of the bridge is $0.43 \mathrm{~m} /$ $\mathrm{s}^{2}$. However, when the speed exceeds $120 \mathrm{~km} / \mathrm{h}$, the acceleration increases from $0.43 \mathrm{~m} / \mathrm{s}^{2}$ to $0.59 \mathrm{~m} / \mathrm{s}^{2}$.

To sum up, the acceleration growth trend of train at a speed of $120 \mathrm{~km} / \mathrm{h}$ is relatively stable and linearly correlated. With the speed higher than $120 \mathrm{~km} / \mathrm{h}$, the acceleration growth trend will suddenly become larger. It is shown that the bridge structure can still meet the test requirements when train speed is below $130 \mathrm{~km} / \mathrm{h}$.

4.3. Acceleration Frequency-Domain Analysis. The acceleration signal of the bridge is analyzed in the frequency domain, which can be obtained by fast Fourier transform to the time domain signal. The peaks value of the acceleration signal in the time domain is processed in the frequency domain by using a real-time spectrum, as shown in Figure 12 . The vibration frequency is mainly concentrated in $0 \sim 80 \mathrm{~Hz}$, the vibration of the bridge is different with different vibration frequencies. In Figure 12, in the range of $60 \sim 110 \mathrm{~km} / \mathrm{h}$, the peak of frequency spectrum was all around
$7 \mathrm{~Hz}$, in range of $120 \sim 130 \mathrm{~km} / \mathrm{h}$, the peak of frequency spectrum was all around $13 \mathrm{~Hz}$. This shows that when the maglev train passes through the bridge, the increase in speed will have a different effect on the bridge vibration. In the range of $60 \sim 120 \mathrm{~km} / \mathrm{h}$, the peak value of the spectrum increases with the increase in velocity, but the increase is slow, when the train speed is $120 \mathrm{~km} / \mathrm{h}$, the peak value in the frequency domain was $0.018 \mathrm{~m} / \mathrm{s}^{2}$. However, in the range of $120 \sim 130 \mathrm{~km} / \mathrm{h}$, the peak value in the frequency domain is $0.026 \mathrm{~m} / \mathrm{s}^{2}$ and grows faster.

In general, as the train speed increases, the frequency signal peak also increases. The frequency-domain signal of acceleration has the same law as the time domain signal.

4.4. Dynamic Deflection. Figure 13 shows the time-history diagram of dynamic deflection of a train passing through $25 \mathrm{~m}$ simply supported box girder. Among them, the eight measured speeds are $60 \mathrm{~km} / \mathrm{h}, 80 \mathrm{~km} / \mathrm{h}, 90 \mathrm{~km} / \mathrm{h}, 100 \mathrm{~km} / \mathrm{h}$, $110 \mathrm{~km} / \mathrm{h}, 120 \mathrm{~km} / \mathrm{h}, 125 \mathrm{~km} / \mathrm{h}$, and $130 \mathrm{~km} / \mathrm{h}$, respectively. It can be seen from the time-history curve of dynamic deflection of simply supported box girder below that at each measured speed of train that the dynamic deflection of $25 \mathrm{~m}$ simply supported box girder in the test section has the same change rule. It goes through three stages, namely, two horizontal sections and a trough section. Three stages of dynamic deflection curve of simply supported box girder correspond to "the stage that the train just enters it," "the stage that the whole train passes through it," and "the stage that the train is about to leave it." "Trough section" refers to the process of downward deflection of simply supported box girder at different train speeds. At this moment, the dynamic deflection value is positive, and its maximum value of midspan lasts for $1 \sim 2 \mathrm{~s}$.

The first horizontal section is the stage that the train just enters the simply supported box girder and does not fully come into it with some distances away from its midspan. Therefore, the midspan dynamic deflection value of simply supported box girder fluctuates above and below zero, which is similar to the level. In the trough section, it is indicated that the whole train enters the simply supported box girder and passes through its midspan. At this moment, the selfweight of the whole train fully acts on its midspan. The downward deflection value reaches the maximum, which lasts for $1 \sim 2 \mathrm{~s}$. At eight speeds of the train, the maximum downward deflection increases with the increase in speed. The second horizontal section is the stage that the train is about to leave. Most trains in this stage almost leave the box girder, and the dynamic deflection value on its midspan fluctuates above zero, which is similar to the level.

However, at train speeds of $60 \mathrm{~km} / \mathrm{h}$ and $80 \mathrm{~km} / \mathrm{h}$, the horizontal section of midspan dynamic deflection curve fluctuates greatly. After analyzing the actual situation on site, it can be concluded that since the train runs at $60 \mathrm{~km} / \mathrm{h}$ and $80 \mathrm{~km} / \mathrm{h}$ in the first and second stages, respectively, it just starts at this time. It is still in the warm-up stage and susceptible to external factors. When it runs at these two speeds, it is less affected by external factors, and the measured dynamic deflection value is relatively stable. A relatively 


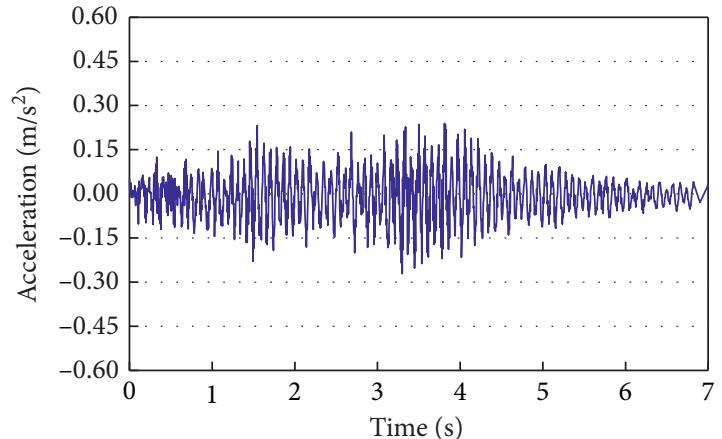

(a)

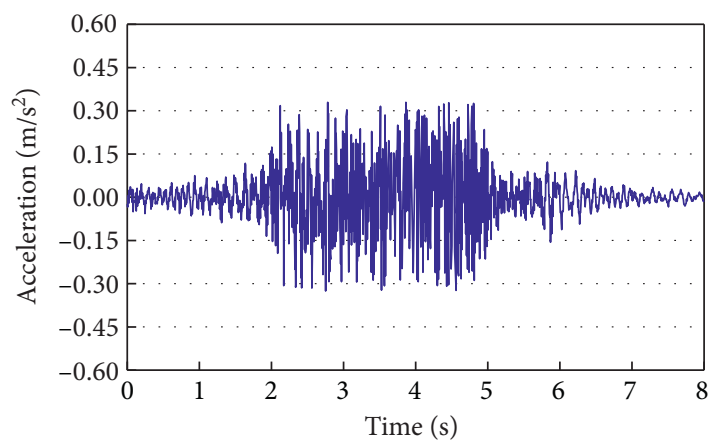

(c)

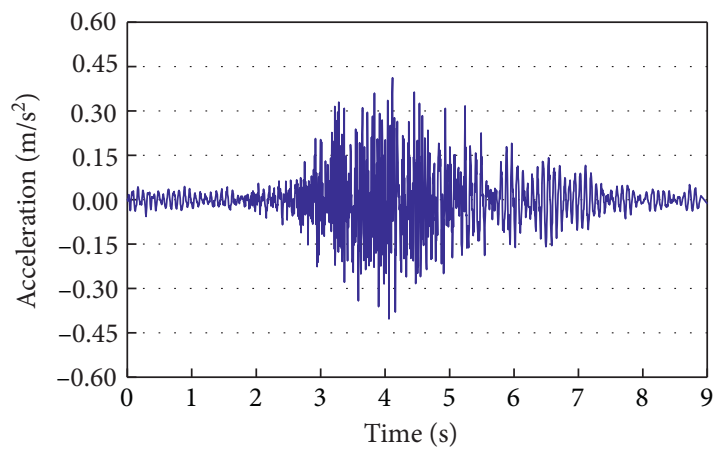

(e)

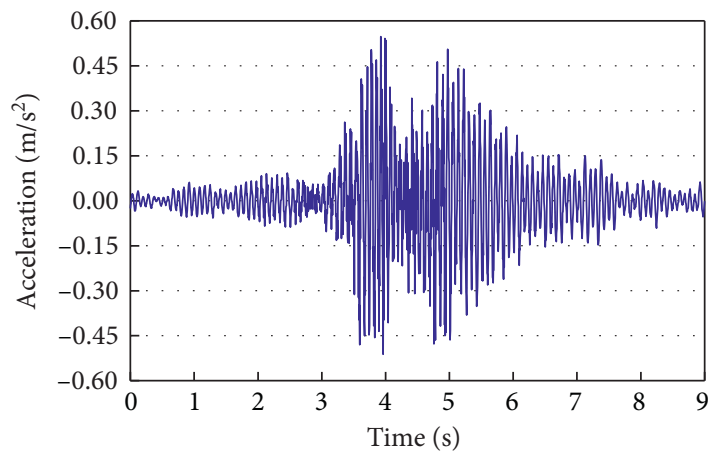

(g)

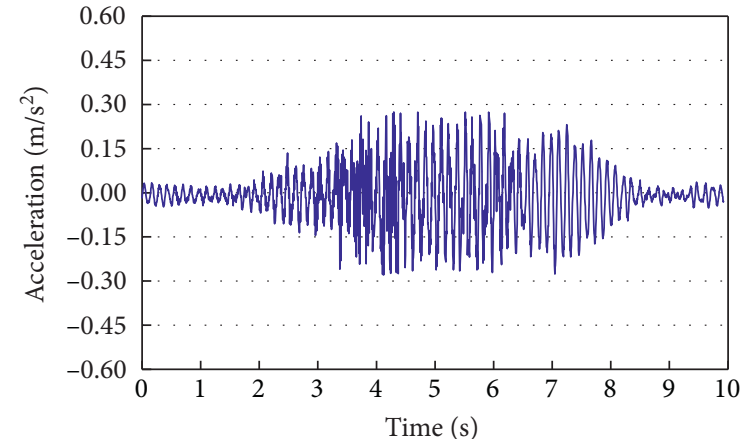

(b)

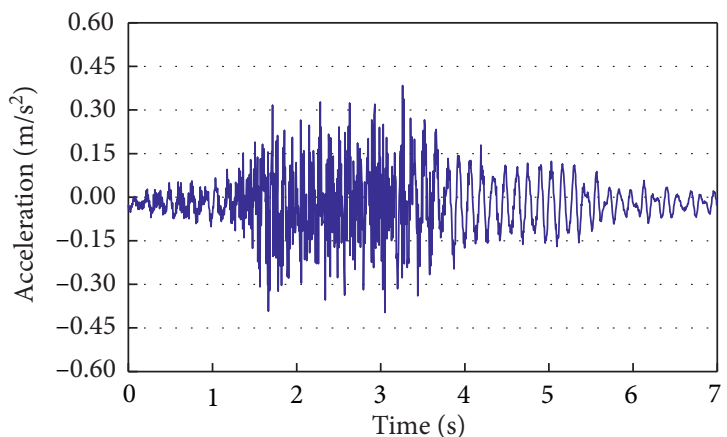

(d)

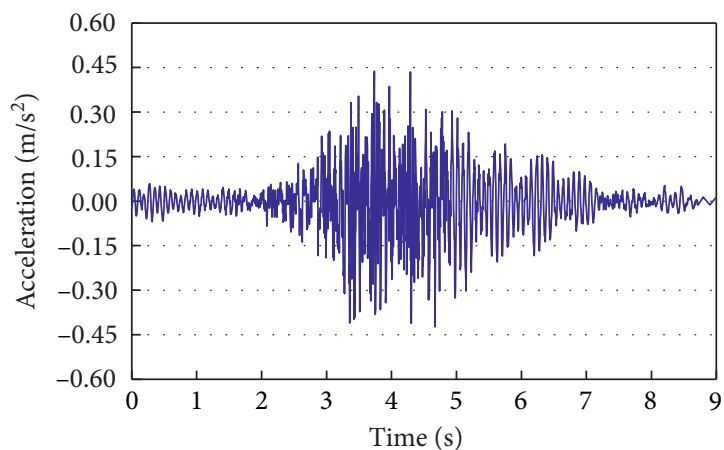

(f)

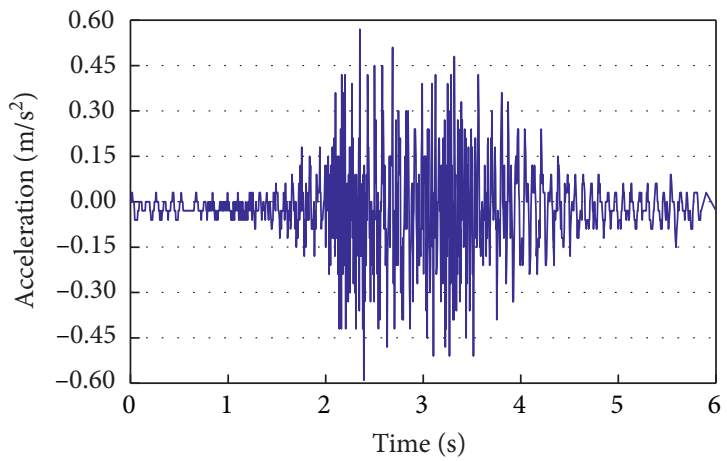

(h)

FiguRE 10: Variation of acceleration at eight different speeds. (a) $v=60 \mathrm{~km} / \mathrm{h}$. (b) $v=80 \mathrm{~km} / \mathrm{h}$. (c) $v=90 \mathrm{~km} / \mathrm{h}$. (d) $v=100 \mathrm{~km} / \mathrm{h}$. (e) $v=110 \mathrm{~km} / \mathrm{h}$. (f) $v=120 \mathrm{~km} / \mathrm{h}$. (g) $v=125 \mathrm{~km} / \mathrm{h}$. (h) $v=130 \mathrm{~km} / \mathrm{h}$.

stable dynamic deflection value of zero is kept in the midspan of simply supported box girder with small fluctuation.
Figure 14 shows the maximum dynamic deflection variation of simply supported box girder at eight speeds. Three growth rates were divided, including $60 \sim 80 \mathrm{~km} / \mathrm{h}$ in 


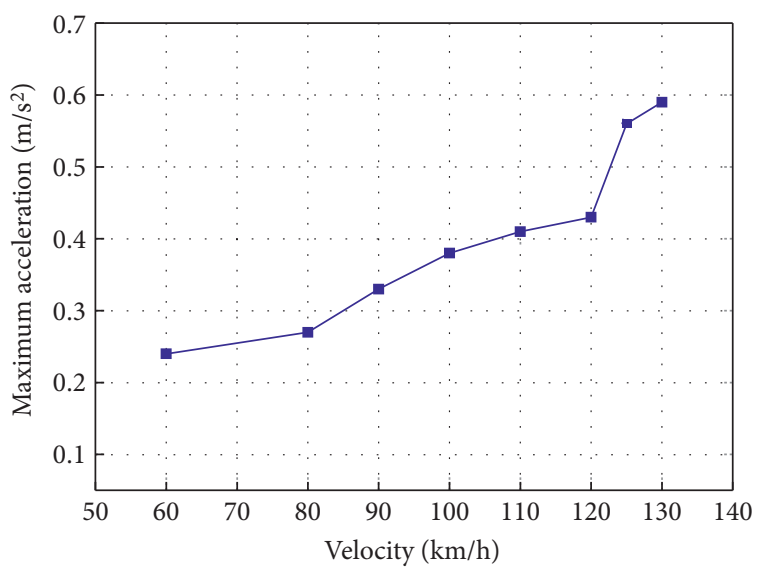

FIGURE 11: Variation of maximum acceleration value at eight different speeds.

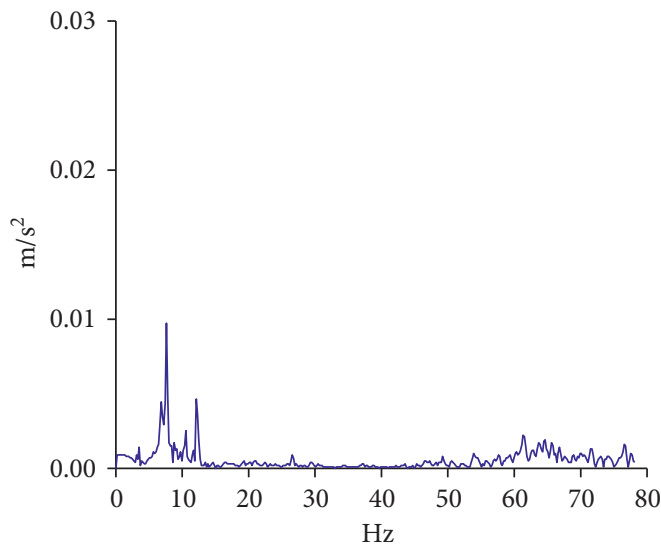

(a)

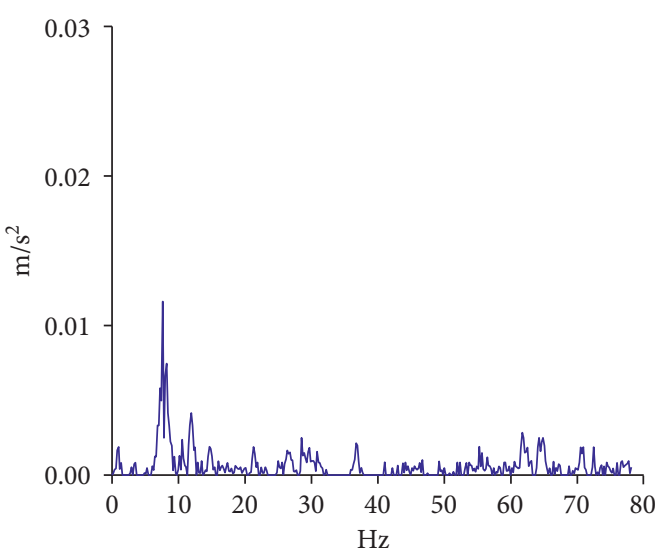

(c)

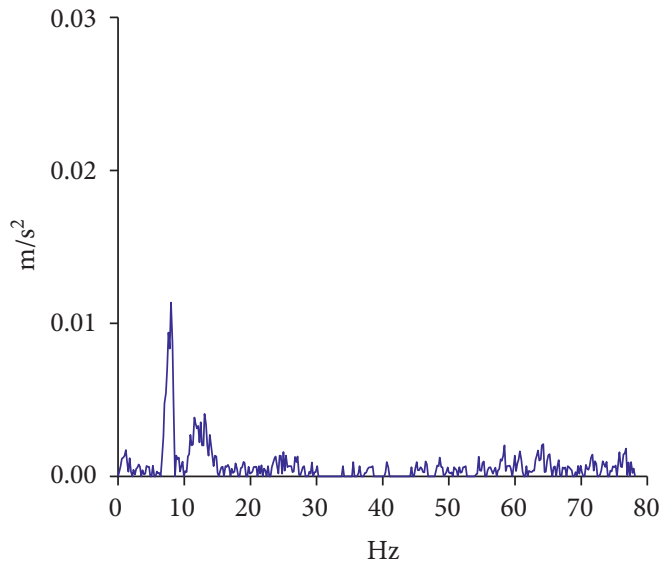

(b)

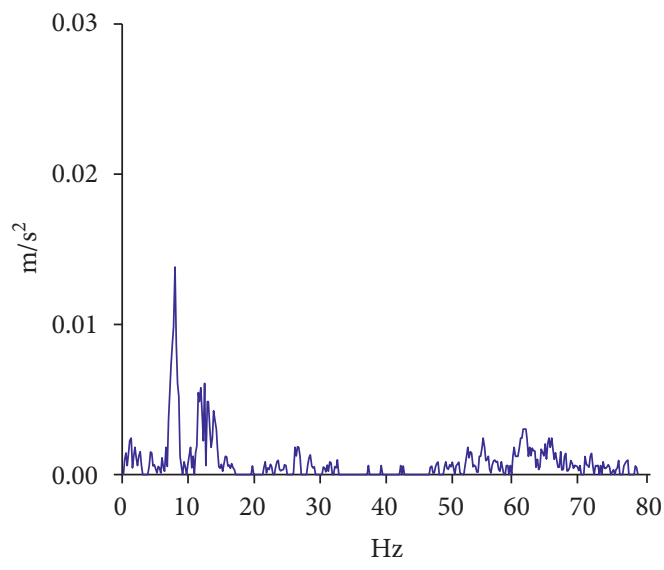

(d)

FIgURE 12: Continued. 


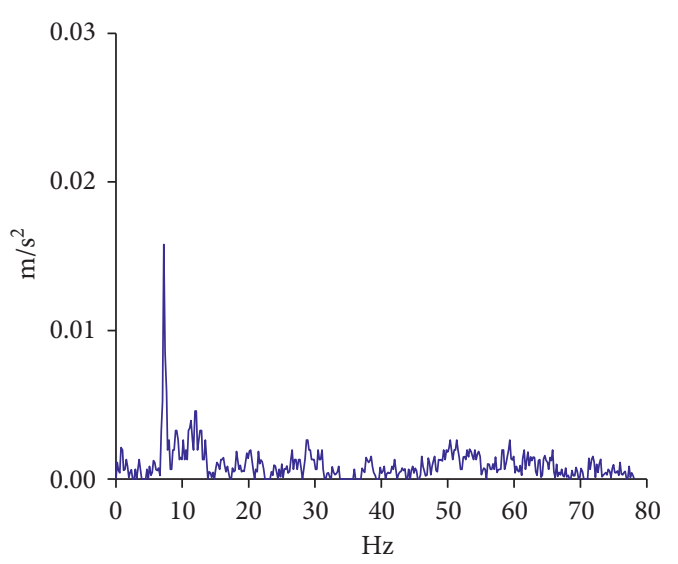

(e)

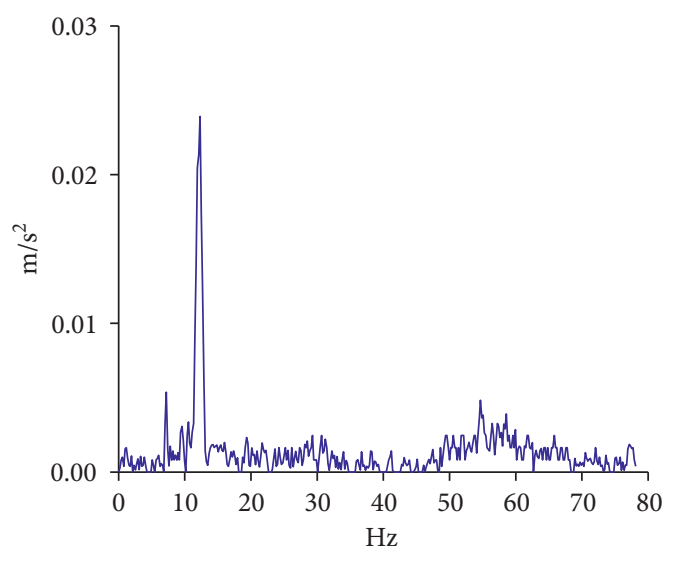

(g)

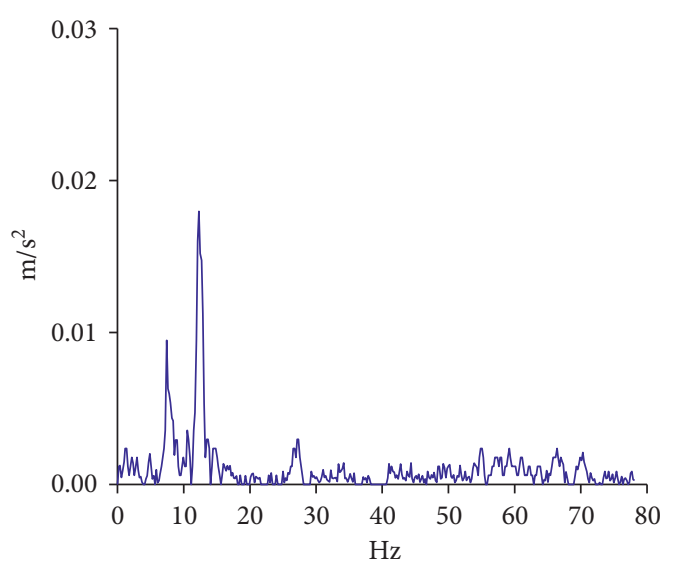

(f)

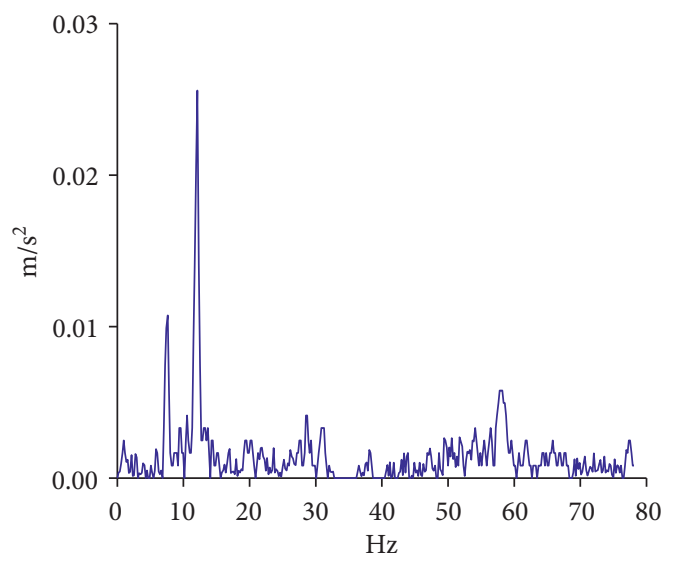

(h)

FIGURE 12: The frequency domain of acceleration at eight different speeds:(a) $v=60 \mathrm{~km} / \mathrm{h}$. (b) $v=80 \mathrm{~km} / \mathrm{h}$. (c) $v=90 \mathrm{~km} / \mathrm{h}$. (d) $v=100 \mathrm{~km} / \mathrm{h}$. (e) $v=110 \mathrm{~km} / \mathrm{h}$. (f) $v=120 \mathrm{~km} / \mathrm{h}$. (g) $v=125 \mathrm{~km} / \mathrm{h}$. (h) $v=130 \mathrm{~km} / \mathrm{h}$.

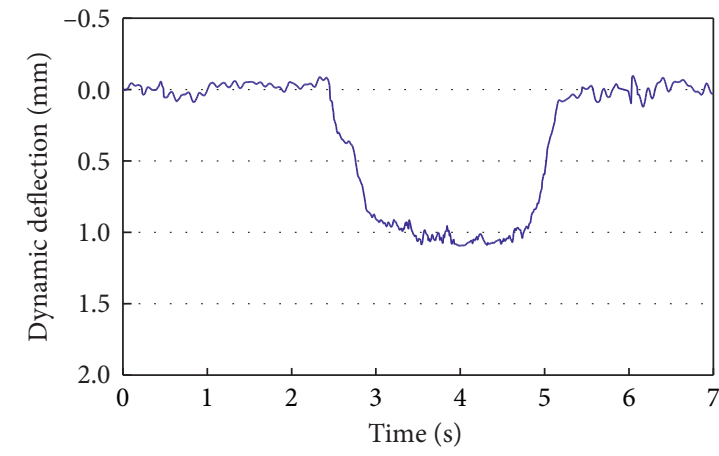

(a)

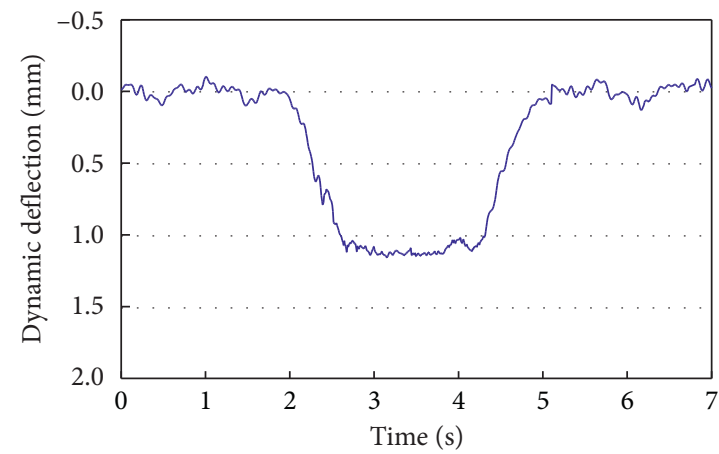

(b)

Figure 13: Continued. 


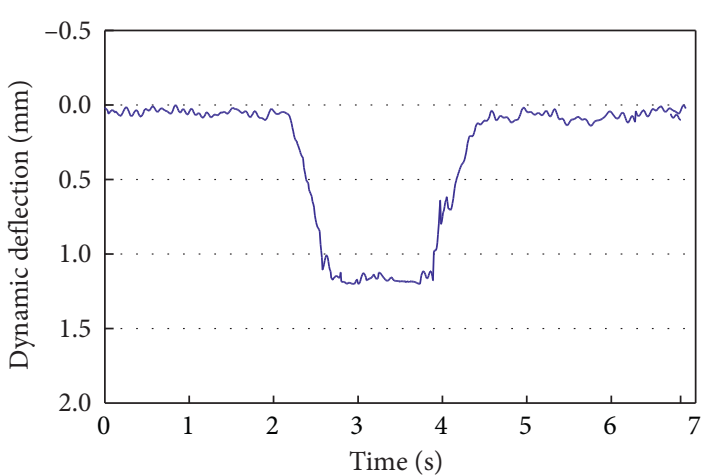

(c)

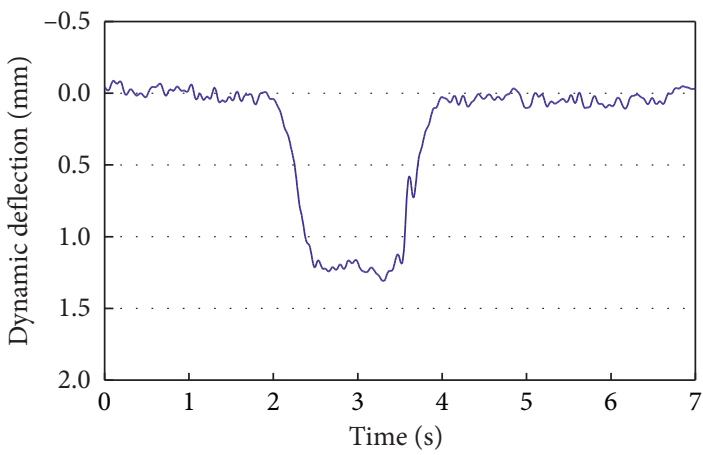

(e)

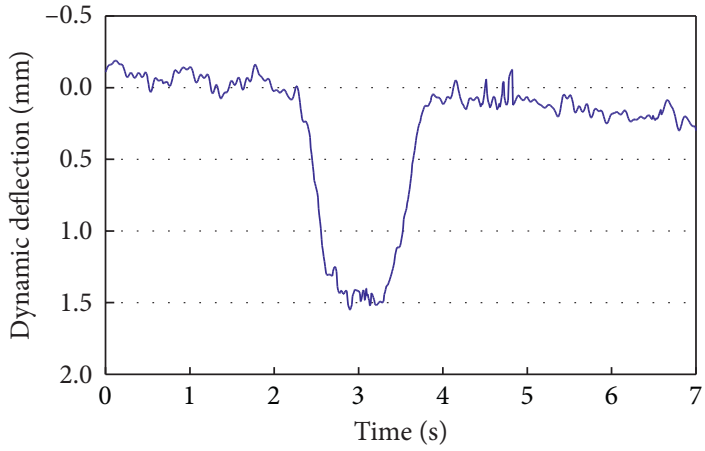

(g)

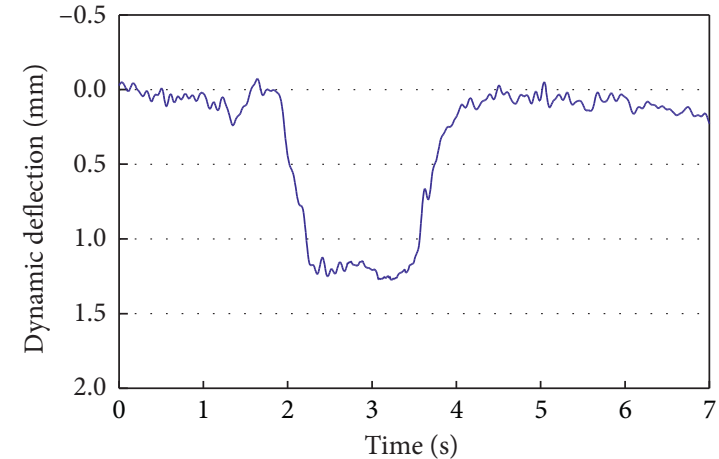

(d)

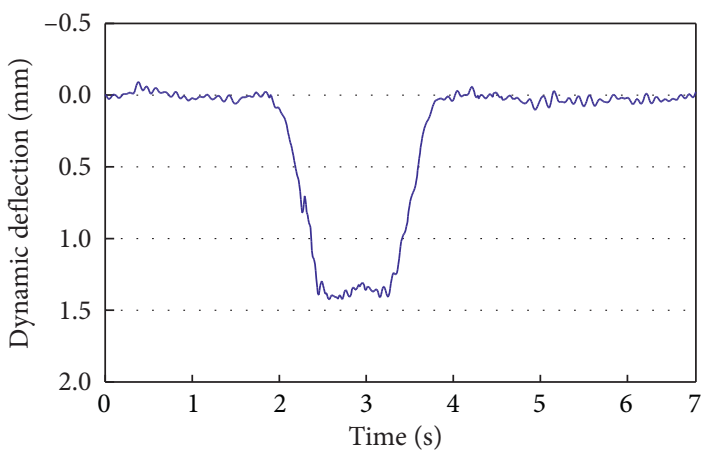

(f)

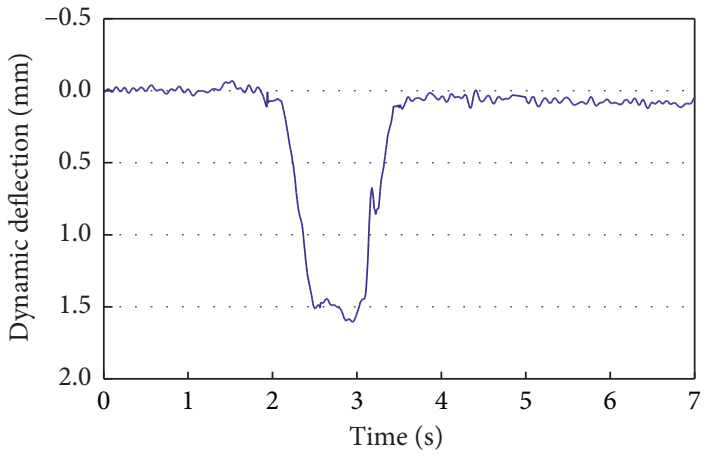

(h)

FIGURE 13: Variation of dynamic deflection at eight different speeds. (a) $v=60 \mathrm{~km} / \mathrm{h}$. (b) $v=80 \mathrm{~km} / \mathrm{h}$. (c) $v=90 \mathrm{~km} / \mathrm{h}$. (d) $v=100 \mathrm{~km} / \mathrm{h}$. (e) $v=110 \mathrm{~km} / \mathrm{h}$. (f) $v=120 \mathrm{~km} / \mathrm{h}$. (g) $v=125 \mathrm{~km} / \mathrm{h}$. (h) $v=130 \mathrm{~km} / \mathrm{h}$.

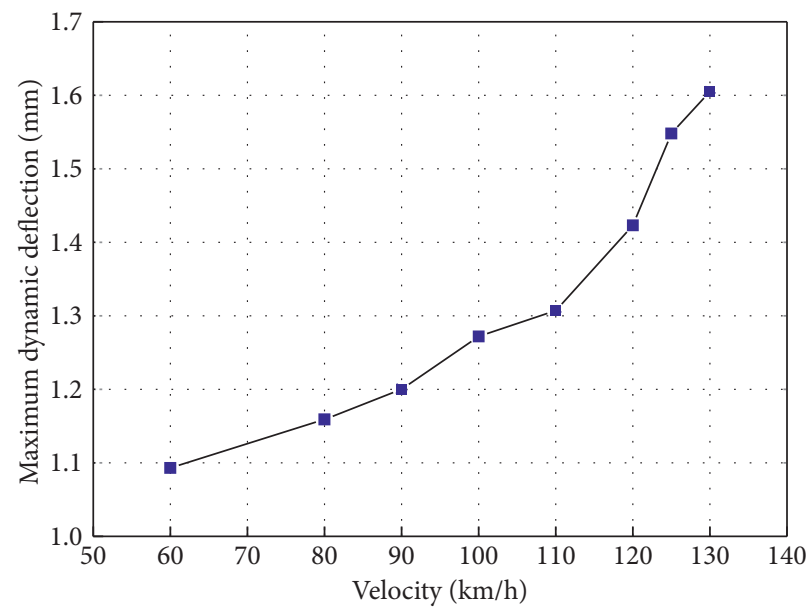

Figure 14: Variation of maximum dynamic deflection value at eight different speeds. 
the first stage with a speed growth range of $20 \mathrm{~km} / \mathrm{h}$, $80 \sim 120 \mathrm{~km} / \mathrm{h}$ in the second stage with a speed growth range of about $10 \mathrm{~km} / \mathrm{h}$, and $120 \sim 130 \mathrm{~km} / \mathrm{h}$ in the third stage with a speed growth range of about $5 \mathrm{~km} / \mathrm{h}$. The increased speed has a great influence on the dynamic deflection of midspan of simply supported box girder. Therefore, it can be divided into three stages with a decreasing growth range.

It can be seen from the above figure that, with the gradual increase in train speed, the maximum dynamic deflection of midspan of simply supported box girder also increases slightly. When the train speed increases to $110 \mathrm{~km} / \mathrm{h}$, the maximum dynamic deflection value increases sharply. It reaches the maximum $1.61 \mathrm{~mm}$ at the speed of $130 \mathrm{~km} / \mathrm{h}$. Among them, with the speed of $110 \mathrm{~km} / \mathrm{h}$ as the cutoff point, two slope diagrams of dynamic deflection can be roughly divided. The slope of the dynamic deflection variation diagram at $110 \sim 130 \mathrm{~km} / \mathrm{h}$ is larger than that of $60 \sim 110 \mathrm{~km} / \mathrm{h}$; that is, the line chart of speed above $110 \mathrm{~km} / \mathrm{h}$ is steeper than that below $110 \mathrm{~km} / \mathrm{h}$.

At the same time, it is also shown that after the train speed exceeds $110 \mathrm{~km} / \mathrm{h}$, the dynamic deflection of midspan of simply supported box girder is greatly affected by the increase in train speed. Therefore, the dynamic deflection varies greatly. The overall performance is that at $110 \mathrm{~km} /$ $\mathrm{h} \sim 130 \mathrm{~km} / \mathrm{h}$, the dynamic deflection variation value is $0.298 \mathrm{~mm}$, which is $0.214 \mathrm{~mm}$ more than that at $60 \sim 110 \mathrm{~km} /$ h. Therefore, the train speed of $110 \mathrm{~km} / \mathrm{h}$ is an important turning point for the midspan deflection variation of the simply supported box girder.

\section{Dynamic Response of Maglev Train}

5.1. Acceleration of Suspension Frame. Figure 15 shows the time-history diagram of acceleration of suspension frame at six speeds, including $60 \mathrm{~km} / \mathrm{h}, 70 \mathrm{~km} / \mathrm{h}, 80 \mathrm{~km} / \mathrm{h}, 100 \mathrm{~km} / \mathrm{h}$, $120 \mathrm{~km} / \mathrm{h}$, and $130 \mathrm{~km} / \mathrm{h}$. It should be noted that this refers to the acceleration diagram of the train after reaching the specified speed and maintaining a constant speed. At six speeds, the acceleration amplitude of the suspension frame can be stabilized in a range, which increases with the increase in speed. At the same time, it can be seen from the timehistory diagram of the suspension frame's acceleration that, with the increase in train speed, the dispersion distribution of its amplitude becomes more obvious, indicating that the increase in train speed makes it more and more disturbed by the influencing factors of the external environment.

When the train speed is $60 \mathrm{~km} / \mathrm{h}, 70 \mathrm{~km} / \mathrm{h}$, and $80 \mathrm{~km} / \mathrm{h}$, respectively, the acceleration amplitude of the suspension frame can be stable within the range of $-1.58 \sim 1.58 \mathrm{~m} / \mathrm{s}^{2}$, which is slightly disturbed by the influencing factors of the external environment. When the train speed increases to $100 \mathrm{~km} / \mathrm{h}$ and $120 \mathrm{~km} / \mathrm{h}$, respectively, the acceleration amplitude of the suspension frame will increase to different degrees, which is stable in the range of $-2.36 \sim 2.36 \mathrm{~m} / \mathrm{s}^{2}$, respectively. In these two speed stages, the suspension frame of the train is more disturbed by external environmental factors than that in $60 \mathrm{~km} / \mathrm{h}$ and $80 \mathrm{~km} / \mathrm{h}$ stages. When the train speed increases to $130 \mathrm{~km} / \mathrm{h}$, respectively, the acceleration amplitude of its suspension frame is stable in the range of $-3.43 \sim 3.43 \mathrm{~m} / \mathrm{s}^{2}$, respectively. Obviously, at this moment, it reaches the maximum at the train speed of $130 \mathrm{~km} / \mathrm{h}$. Compared with the previous five speeds, the acceleration amplitude of the suspension frame at $130 \mathrm{~km} / \mathrm{h}$ is most disturbed by external environmental factors, which is manifested in the most obvious dispersion distribution of acceleration amplitude.

In a word, the increase in train speed makes the acceleration amplitude of the suspension frame vary more; that is, the dispersion distribution is more obvious, indicating that the suspension frame is greatly disturbed by external environmental factors. However, the acceleration amplitude can be stable within a range in the end.

Figure 16 shows the variation of maximum acceleration of suspension frame at each speed. It can be seen from the figure that the maximum acceleration of the suspension frame increases with the increase in train speed. However, when the train speed reaches more than $120 \mathrm{~km} / \mathrm{h}$, the maximum acceleration of the suspension frame increases, indicating that the increase in the speed of the train has a great influence on the acceleration of the suspension frame.

5.2. Gap of Suspension Frame. In this section, the gap of suspension frame will be analyzed and its change rules will be explored at different speeds, respectively, including $60 \mathrm{~km} / \mathrm{h}, 80 \mathrm{~km} / \mathrm{h}, 100 \mathrm{~km} / \mathrm{h}, 120 \mathrm{~km} / \mathrm{h}, 125 \mathrm{~km} / \mathrm{h}$, and $130 \mathrm{~km} / \mathrm{h}$, as shown in Figure 17.

It can be seen from Figure 17 that, with the increase in train speed, the maglev gap shows an increasing trend. At $125 \mathrm{~km} / \mathrm{h}$, it reaches the maximum and then decreases. When the train speed is at $60 \mathrm{~km} / \mathrm{h}$, it is between $8.35 \mathrm{~mm}$ and $10.71 \mathrm{~m}$, which is mainly distributed in $8.65 \mathrm{~mm}$ to $10.24 \mathrm{~mm}$. The disturbance is very small and the train is relatively stable. When the train speed reaches $80 \mathrm{~km} / \mathrm{h}$, it is between $7.40 \mathrm{~mm}$ and $11.80 \mathrm{~mm}$, which is mainly distributed in $8.03 \mathrm{~mm}$ to $10.87 \mathrm{~mm}$. Its range at this speed is larger than that at $60 \mathrm{~km} / \mathrm{h}$, but the trains are still able to run smoothly. When the train speed increases to $100 \mathrm{~km} / \mathrm{h}$, it is between $7.09 \mathrm{~mm}$ and $11.97 \mathrm{~mm}$, which is mainly distributed in $8.19 \mathrm{~mm}$ to $11.34 \mathrm{~mm}$. Its range at this speed is further expanded compared with that at $80 \mathrm{~km} / \mathrm{h}$.

When the train speed is $120 \mathrm{~km} / \mathrm{h}$, the maglev gap is between $6.93 \mathrm{~mm}$ and $12.6 \mathrm{~mm}$, which is mainly distributed in $7.40 \mathrm{~mm}$ to $11.50 \mathrm{~mm}$. When the train speed is $125 \mathrm{~km} / \mathrm{h}$, it is between $7.24 \mathrm{~mm}$ and $13.70 \mathrm{~mm}$, which is mainly distributed in $7.24 \mathrm{~mm}$ to $11.50 \mathrm{~mm}$. At this time, the fluctuation range of maglev gap is further expanded. When the train speed is $130 \mathrm{~km} / \mathrm{h}$, it is between $7.24 \mathrm{~mm}$ and $12.76 \mathrm{~mm}$, which is mainly distributed in $7.24 \mathrm{~mm}$ to $11.5 \mathrm{~mm}$. At this time, there is little difference in the main area. 


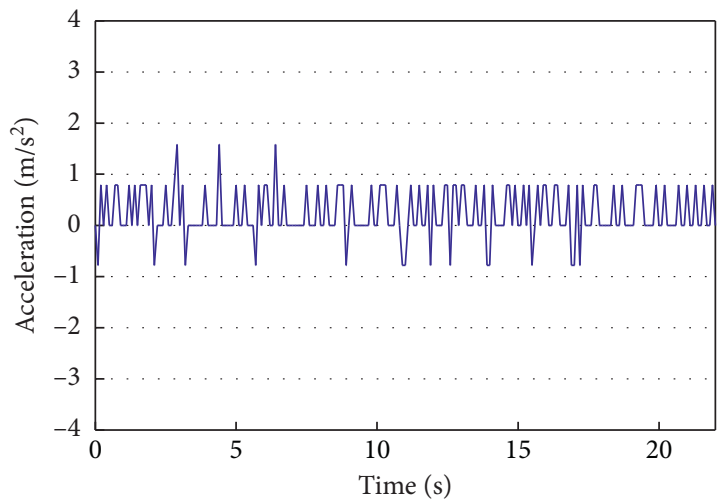

(a)

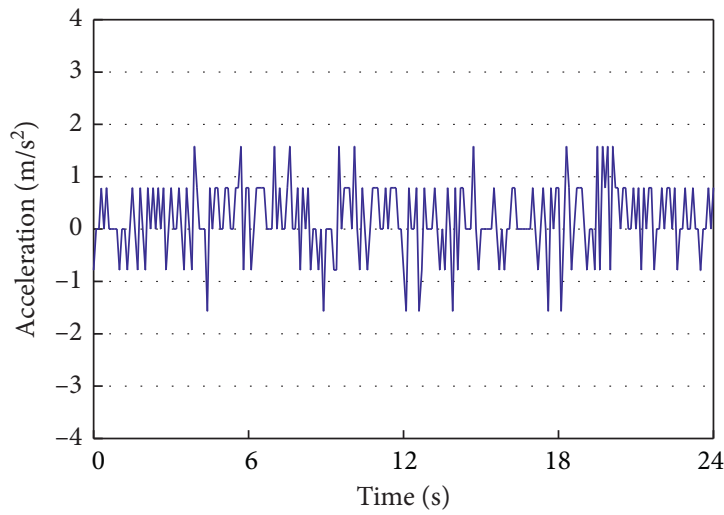

(c)

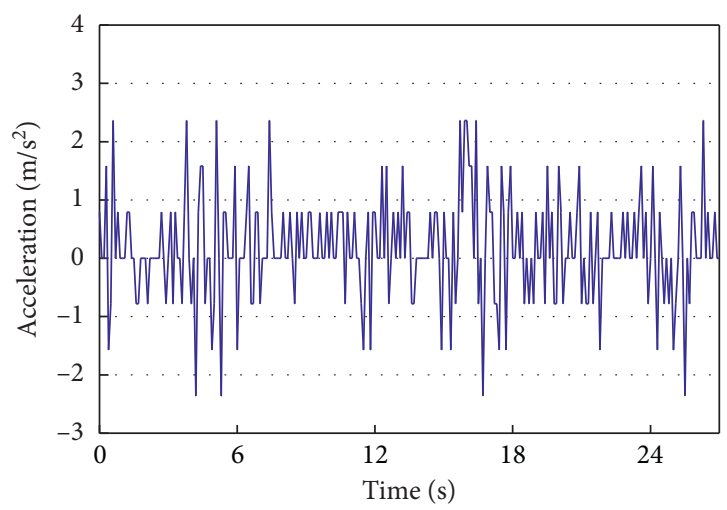

(e)

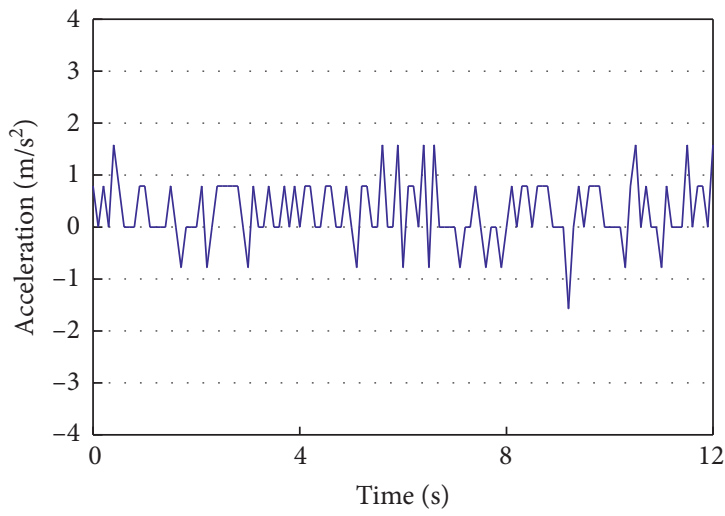

(b)

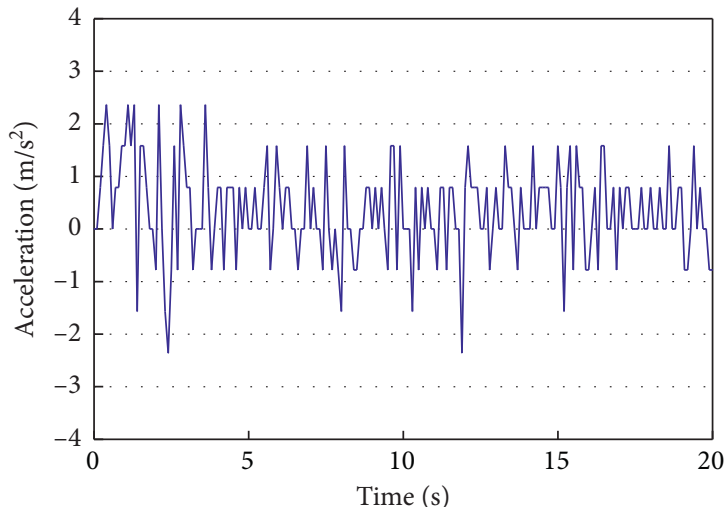

(d)

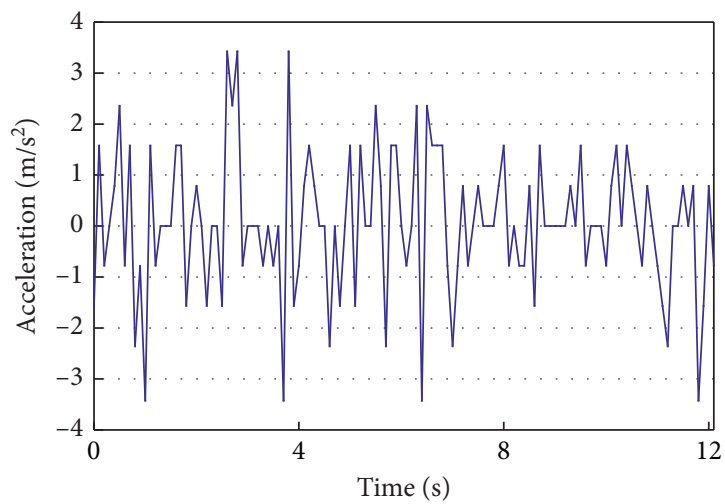

(f)

FiguRE 15: Variation of acceleration of suspension frame at six different speeds. (a) $v=60 \mathrm{~km} / \mathrm{h}$. (b) $v=70 \mathrm{~km} / \mathrm{h}$. (c) $v=80 \mathrm{~km} / \mathrm{h}$. (d) $v=100 \mathrm{~km} / \mathrm{h}$. (e) $v=120 \mathrm{~km} / \mathrm{h}$. (f) $v=130 \mathrm{~km} / \mathrm{h}$.

Figure 18 shows the variations of maximum and minimum maglev gaps. It can be seen from the figure that the maximum maglev gap is $13.7 \mathrm{~mm}$ with the increase in train speed within the range of $60 \sim 130 \mathrm{~km} / \mathrm{h}$, which increases by $5.2 \mathrm{~mm}$ compared with $8.5 \mathrm{~mm}$ in static floating. The minimum maglev gap is $6.93 \mathrm{~mm}$, which is $1.57 \mathrm{~mm}$ less than that in static floating. The safety range of maglev gap is known to be in the range of $0 \sim 18 \mathrm{~mm}$. Therefore, when the train runs at $130 \mathrm{~km} / \mathrm{h}$, its suspension frame is always within the normal range. 


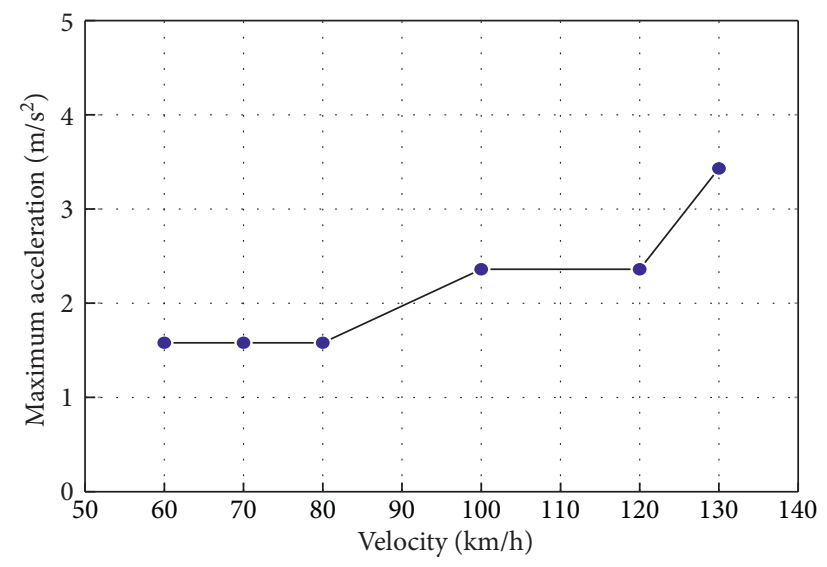

FIGURE 16: Variation of maximum acceleration of suspension frame at six different speeds.

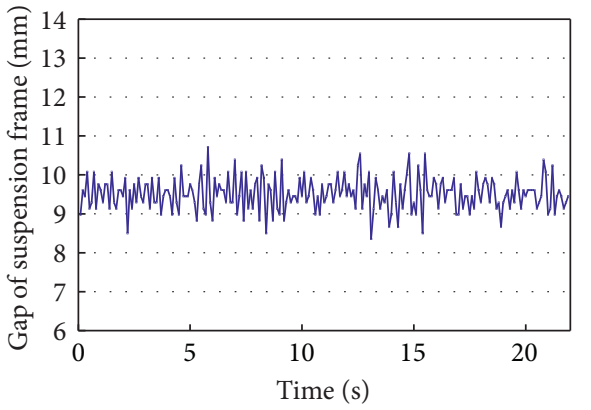

(a)

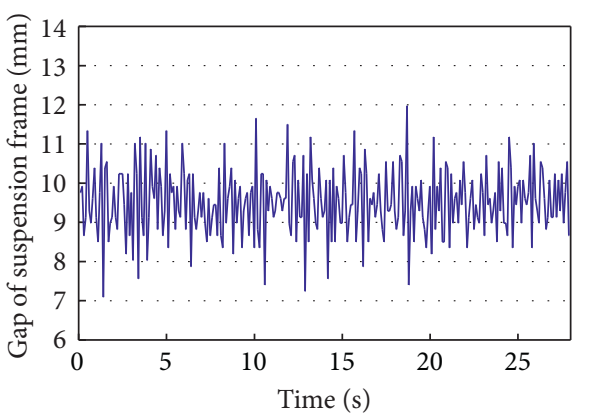

(c)

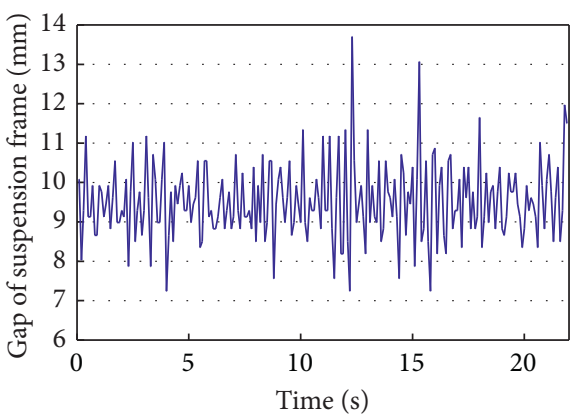

(e)

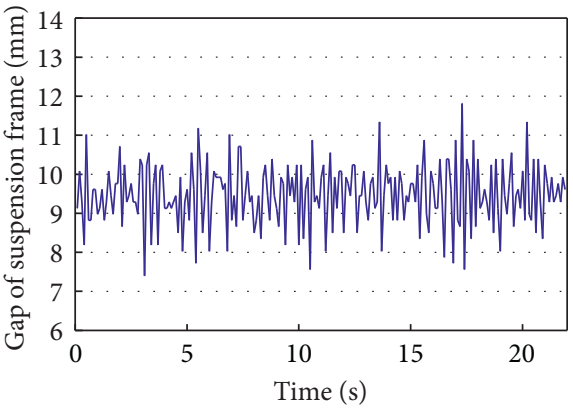

(b)

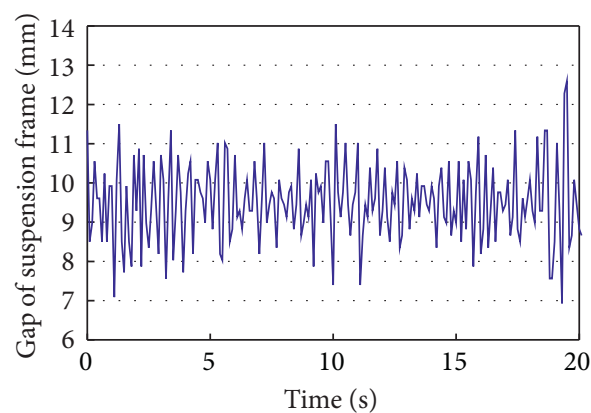

(d)

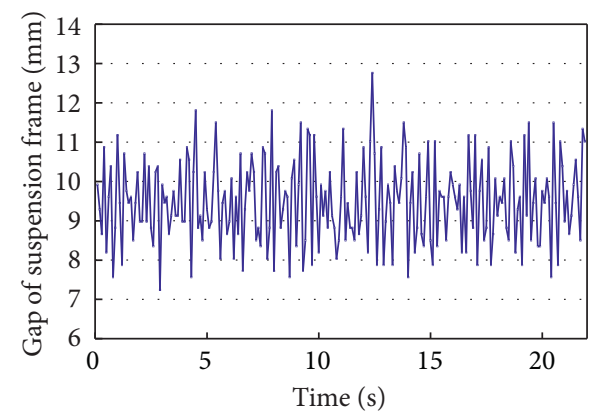

(f)

FiguRE 17: Variation of gap value of suspension frame at six different speeds. (a) $v=60 \mathrm{~km} / \mathrm{h}$. (b) $v=80 \mathrm{~km} / \mathrm{h}$. (c) $v=100 \mathrm{~km} / \mathrm{h}$. (d) $v=120 \mathrm{~km} / \mathrm{h}$. (e) $v=125 \mathrm{~km} / \mathrm{h}$. (f) $v=130 \mathrm{~km} / \mathrm{h}$. 


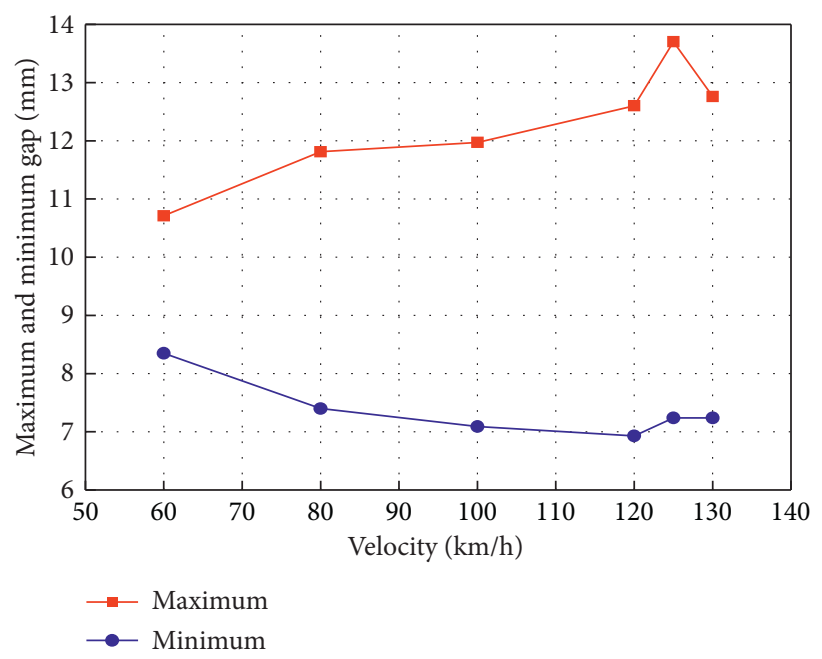

FIGURE 18: Variations of maximum and minimum gap values of the suspension frame at six different speeds.

\section{Conclusion}

(1) Based on the dynamic strain analysis of bridge structure, it can be concluded that the dynamic strain will increase suddenly when the train passes through the simply supported box girder at each speed. Then, it will be stable and decrease slowly finally. When the train speed is below $100 \mathrm{~km} / \mathrm{h}$, the dynamic strain changes slightly. When the speed exceeds $100 \mathrm{~km} / \mathrm{h}$, it slightly increases, but less affected by the increase in train speed overall.

(2) The acceleration analysis of bridge structure shows that within $60 \sim 120 \mathrm{~km} / \mathrm{h}$, the acceleration increases linearly with the speed of the train. When the speed exceeds $120 \mathrm{~km} / \mathrm{h}$, the acceleration increases suddenly. The bridge structure can meet the requirements of the safe operation of the train.

(3) The vibration frequency of the bridge structure is mainly concentrated in $0 \sim 80 \mathrm{~Hz}$. When the maglev train speed is in the range of $60 \sim 110 \mathrm{~km} / \mathrm{h}$, the sensitive frequency of the bridge structure is around $7 \mathrm{~Hz}$. When the maglev train speed is in the range of $120 \sim 130 \mathrm{~km} / \mathrm{h}$, the sensitive frequency of the bridge structure is $13 \mathrm{~Hz}$.

(4) By analyzing the dynamic deflection of the bridge structure, with the increase in speed, the maximum dynamic deflection of the midspan of simply supported box girder also increases. In addition, the train speed of $110 \mathrm{~km} / \mathrm{h}$ is an important turning point for the midspan deflection variation of the simply supported box girder.

(5) From the acceleration analysis of the suspension frame, when the train speed reaches more than $120 \mathrm{~km} / \mathrm{h}$, the maximum acceleration of the suspension frame increases, indicating that the increase in train speed has a great influence on the acceleration of the suspension frame.
(6) It is found in the analysis of the maglev gap that the amplitude of the maglev gap varies greatly with the increase in train speed. When the train speed reaches $120 \mathrm{~km} / \mathrm{h}$, the disturbance is relatively obvious, which is concentrated in the range of $7.24 \sim 11.50 \mathrm{~mm}$ at last. Compared with $8.5 \mathrm{~mm}$ of static floating, the maglev gap is still within the normal range and the train can still run normally.

\section{Data Availability}

All the original measured data in this paper can be obtained legally and reasonably from the corresponding author.

\section{Disclosure}

Dr. Liang and Dr. Jiang are considered as the co-first authors

\section{Conflicts of Interest}

The authors declare that there are no conflicts of interest.

\section{Authors' Contributions}

Dr. Liang and Dr. Jiang contributed equally to this manuscript.

\section{Acknowledgments}

This research was funded by the National Nature Science Foundation of China (Grant nos. 51778068 and 51678069), the Hunan Nature Science Foundation of China (Grant no. 2019JJ40301), the Hunan Special Funds for the Construction of Innovative Provinces of China (Grant no. 2019SK2171), the Scientific Research Fund of Hunan Provincial Education Department of China (Grant no. 17A010), the Major Technological Achievements Transformation Program of Hunan Strategic Emerging Industries of China (Grant no. 
2017GK4034), and the Double Top-Class International Cooperation Scientific Research Fund of Changsha University of Science and Technology of China (Grant no. 2018IC18).

\section{References}

[1] H. Alscher, M. Iguchi, A. R. Eastham, and I. Boldea, "Noncontact suspension and propulsion technology," Vehicle System Dynamics, vol. 12, no. 4-5, pp. 259-289, 1983.

[2] X. Li, D. Wang, D. Liu, L. Xin, and X. Zhang, "Dynamic analysis of the interactions between a low-to-medium-speed maglev train and a bridge: field test results of two typical bridges," Proceedings of the Institution of Mechanical Engineers, Part F: Journal of Rail and Rapid Transit, vol. 232, no. 7, pp. 2039-2059, 2018.

[3] S. Yamamura, "Magnetic levitation technology of tracked vehicles present status and prospects," IEEE Transactions on Magnetics, vol. 12, no. 6, pp. 874-878, 1976.

[4] E. Gottzein and B. Lange, "Magnetic suspension control systems for the MBB high speed train," Automatica, vol. 11, no. 3, pp. 271-284, 1975.

[5] E. Gottzein, K.-H. Brock, E. Schneider, and J. Pfefferl, "Control aspects of a tracked magnetic levitation high speed test vehicle," Automatica, vol. 13, no. 3, pp. 205-223, 1977.

[6] E. Gottzein, R. Meisinger, and L. Miller, "The Magnetic wheel" in the suspension of high-speed ground transportation vehicles," IEEE Transactions on Vehicular Technology, vol. 29, no. 1, pp. 17-23, 1980.

[7] J.-B. Han, H.-S. Han, S.-S. Kim, S.-J. Yang, and K.-J. Kim, "Design and validation of a slender guideway for maglev vehicle by simulation and experiment," Vehicle System Dynamics, vol. 54, no. 3, pp. 370-385, 2016.

[8] J.-S. Lee, S.-D. Kwon, M.-Y. Kim, and I. H. Yeo, “A parametric study on the dynamics of urban transit maglev vehicle running on flexible guideway bridges," Journal of Sound and Vibration, vol. 328, no. 3, pp. 301-317, 2009.

[9] E. Kong, J.-S. Song, B.-B. Kang, and S. Na, "Dynamic response and robust control of coupled maglev vehicle and guideway system," Journal of Sound and Vibration, vol. 330, no. 25, pp. 6237-6253, 2011.

[10] J. Shi, Q. Wei, and Y. Zhao, "Analysis of dynamic response of the high-speed EMS maglev vehicle/guideway coupling system with random irregularity," Vehicle System Dynamics, vol. 45, no. 12, pp. 1077-1095, 2007.

[11] J. Shi and Y.-J. Wang, "Dynamic response analysis of singlespan guideway caused by high speed maglev train," Latin American Journal of Solids and Structures, vol. 8, no. 3, pp. 213-228, 2011.

[12] J. Kim, C.-W. Ha, G. B. King, and C.-H. Kim, "Experimental development of levitation control for a high-accuracy magnetic levitation transport system," ISA Transactions, vol. 101, 2020.

[13] P. Schmin, P. Eberhard, and F. Dignath, "Nonlinear model predictive control for a maglev vehicle regarding magnetic saturation and guideway irregularities," IFAC-PapersOnline, vol. 52, no. 52, 2019.

[14] L. Zhang and J. Huang, "Dynamic interaction analysis of the high-speed maglev vehicle/guideway system based on a field measurement and model updating method," Engineering Structures, vol. 180, 2019.

[15] J. F. Wilson and S. B. Biggers, "Dynamic interactions between long, high speed trains of air cushion vehicles and their guideways," Journal of Dynamic Systems, Measurement, and Control, vol. 93, no. 1, pp. 16-24, 1971.

[16] W. S. Chiu, R. G. Smith, and D. N. Wormley, "Influence of vehicle and distributed guideway parameters on high speed vehicle-guideway dynamic interactions," Journal of Dynamic Systems, Measurement, and Control, vol. 93, no. 1, pp. 25-34, 1971.

[17] R. M. Katz, V. D. Nene, R. J. Ravera, and C. A. Skalski, "Performance of magnetic suspensions for high speed vehicles operating over flexible guideways," Journal of Dynamic Systems, Measurement, and Control, vol. 96, no. 2, pp. 204-212, 1974.

[18] C. C. Smith and D. N. Wormley, "Response of continuous periodically supported guideway beams to traveling vehicle loads," Journal of Dynamic Systems, Measurement, and Control, vol. 97, no. 1, pp. 21-29, 1975.

[19] Y. Cai, S. S. Chen, D. M. Rote, and H. T. Coffey, "Vehicle/ guideway interaction for high speed vehicles on a flexible guideway," Journal of Sound and Vibration, vol. 175, no. 5, pp. 625-646, 1994.

[20] J. D. Yau, "Aerodynamic vibrations of a maglev vehicle running on flexible guideways under oncoming wind actions," Journal of Sound and Vibration, vol. 329, no. 10, pp. 1743-1759, 2010.

[21] J. D. Yau, "Lateral vibration control of a low-speed maglev vehicle in cross winds," Wind and Structures An International Journal, vol. 15, no. 3, pp. 263-283, 2012.

[22] S.-D. Kwon, J.-S. Lee, J.-W. Moon, and M.-Y. Kim, "Dynamic interaction analysis of urban transit maglev vehicle and guideway suspension bridge subjected to gusty wind," Engineering Structures, vol. 30, no. 12, pp. 3445-3456, 2008.

[23] K.-J. Kim, J.-B. Han, H.-S. Han, and S.-J. Yang, "Coupled vibration analysis of maglev vehicle-guideway while standing still or moving at low speeds," Vehicle System Dynamics, vol. 53, no. 4, pp. 587-601, 2015.

[24] J. Li, J. Li, D. Zhou, and L. Wang, "The modeling and analysis for the self-excited vibration of the maglev vehicle-bridge interaction system," Mathematical Problems in Engineering, vol. 2015, Article ID 709583, 10 pages, 2015.

[25] D. F. Zhou, C. H. Zhou, J. Li, and W. S. Chang, "Review of coupled vibration problems in EMS maglev vehicles," International Journal of Acoustics and Vibration, vol. 15, no. 1, pp. 10-23, 2010.

[26] J.-h. Li, J. Li, and G. Zhang, "A practical robust nonlinear controller for maglev levitation system," Journal of Central South University, vol. 20, no. 11, pp. 2991-3001, 2013. 